\title{
Integration of Hypernatremia and Angiotensin II by the Organum Vasculosum of the Lamina Terminalis Regulates Thirst
}

\author{
Brian J. Kinsman, ${ }^{1,2}$ Sarah S. Simmonds, ${ }^{2}$ Kirsteen N. Browning, ${ }^{2}$ Megan M. Wenner, ${ }^{3}$ William B. Farquhar, ${ }^{3}$ \\ and $\mathbb{D}$ Sean D. Stocker ${ }^{1}$ \\ ${ }^{1}$ Division of Renal-Electrolyte, Department of Medicine, University of Pittsburgh, Pittsburgh, Pennsylvania 15213, ${ }^{2}$ Department of Neural and Behavioral \\ Sciences, Penn State College of Medicine, Hershey, Pennsylvania 17033, and ${ }^{3}$ Department of Kinesiology and Applied Physiology, University of Delaware, \\ Newark, Delaware 19713
}

The organum vasculosum of the lamina terminalis (OVLT) contains NaCl-sensitive neurons to regulate thirst, neuroendocrine function, and autonomic outflow. The OVLT also expresses the angiotensin II (AngII) type1 receptor, and AngII increases Fos expression in OVLT neurons. The present study tested whether individual OVLT neurons sensed both $\mathrm{NaCl}$ and AngII to regulate thirst and body fluid homeostasis. A multifaceted approach, including in vitro whole-cell patch recordings, in vivo single-unit recordings, and optogenetic manipulation of OVLT neurons, was used in adult, male Sprague Dawley rats. First, acute intravenous infusion of hypertonic NaCl or AngII produced anatomically distinct patterns of Fos-positive nuclei in the OVLT largely restricted to the dorsal cap versus vascular core, respectively. However, in vitro patch-clamp recordings indicate 66\% (23 of 35) of OVLT neurons were excited by bath application of both hypertonic $\mathrm{NaCl}$ and AngII. Similarly, in vivo single-unit recordings revealed that $52 \%$ (23 of 44$)$ of OVLT neurons displayed an increased discharge to intracarotid injection of both hypertonic $\mathrm{NaCl}$ and AngII. In marked contrast to Fos immunoreactivity, neuroanatomical mapping of Neurobiotin-filled cells from both in vitro and in vivo recordings revealed that NaCl- and AngII-responsive neurons were distributed throughout the OVLT. Next, optogenetic excitation of OVLT neurons stimulated thirst but not salt appetite. Conversely, optogenetic inhibition of OVLT neurons attenuated thirst stimulated by hypernatremia or elevated AngII but not hypovolemia. Collectively, these findings provide the first identification of individual OVLT neurons that respond to both elevated $\mathrm{NaCl}$ and AngII concentrations to regulate thirst and body fluid homeostasis.

Key words: angiotensin II; hypothalamus; salt appetite; sodium; thirst

\section{Significance Statement}

Body fluid homeostasis requires the integration of neurohumoral signals to coordinate behavior, neuroendocrine function, and autonomic function. Extracellular $\mathrm{NaCl}$ concentrations and the peptide hormone angiotensin II (AngII) are two major neurohumoral signals that regulate body fluid homeostasis. Herein, we present the first compelling evidence that individual neurons located in the organum vasculosum of the lamina terminalis detect both $\mathrm{NaCl}$ and AngII. Furthermore, optogenetic interrogations demonstrate that these neurons play a pivotal role in the regulation of thirst stimulated by $\mathrm{NaCl}$ and AngII. These novel observations lay the foundation for future investigations for how such inputs as well as others converge onto unique organum vasculosum of the lamina terminalis neurons to coordinate body fluid homeostasis and contribute to disorders of fluid balance.

\section{Introduction}

The forebrain lamina terminalis is indispensable to body fluid homeostasis, including thirst and salt appetite, neuroendocrine function, and autonomic regulation (McKinley et al., 2003; Bourque, 2008; Kinsman et al., 2017a; Zimmerman et al., 2017). The lamina terminalis includes the organum vasculosum of the 
lamina terminalis (OVLT), median preoptic nucleus, and subfornical organ (SFO). As sensory circumventricular organs, the OVLT and SFO lack a complete blood-brain barrier and, consequently, sense and respond to changes in electrolyte concentrations and neurohumoral factors in the blood and cerebrospinal fluid (CSF) (McKinley et al., 2003; Bourque, 2008; Toney and Stocker, 2010). While not a circumventricular organ, the median preoptic nucleus is juxtaposed and densely innervated by the OVLT and SFO to function as an integration site with output to hypothalamic, thalamic, and cortical structures to impact body fluid homeostasis (McKinley et al., 2003; Bourque, 2008; Kinsman et al., 2017a; Zimmerman et al., 2017).

The primary homeostatic signals to initiate thirst through the SFO and OVLT are osmolality (or $\mathrm{NaCl}$ concentration) and circulating angiotensin II (AngII) (McKinley et al., 2003; Bourque, 2008; Toney and Stocker, 2010; Zimmerman et al., 2017). Historically, osmosensory versus AngII-responsive neurons represent separate populations. Within OVLT, acute hypernatremia and AngII increase Fos expression but in anatomically distinct populations primarily distributed in the dorsal cap versus the vascular core, respectively (Oldfield et al., 1991, 1994; McKinley et al., 1992; Shi et al., 2008). Hypertonic $\mathrm{NaCl}$ and AngII also increase Fos in anatomical distinct regions of the SFO and primarily located in the lateral margins versus central core, respectively (Oldfield et al., 1991, 1994; McKinley et al., 1992; Shi et al., 2008). On the other hand, recent molecular phenotyping and chemogenetic/optogenetic interrogations demonstrate that $\mathrm{NaCl}-$ and AngII-responsive neurons in the OVLT and SFO may represent overlapping populations. First, OVLT and SFO thirst-promoting neurons are predominantly excitatory and express vesicular glutamate transporter-2, calmodulin kinase IIa (CaMKIIa), and neuronal nitric oxide synthase (Betley et al., 2015; Oka et al., 2015; Nation et al., 2016; Zimmerman et al., 2016; Leib et al., 2017; Augustine et al., 2018). These neuronal populations, particularly nitric oxide synthase-positive cells, respond to hypertonic $\mathrm{NaCl}$ or AngII as revealed by Fos, in vivo calcium imaging, and photometry in mice (Zimmerman et al., 2016; Leib et al., 2017; Augustine et al., 2018). Furthermore, hypertonic $\mathrm{NaCl}$ increases Fos expression in AngII type 1 receptor-expressing neurons of the OVLT as revealed by a reporter mouse (Leib et al., 2017). Thus, these recent findings raise the possibility that individual OVLT neurons may respond to both $\mathrm{NaCl}$ and AngII to alter body fluid homeostasis.

To address this question, we used a multifaceted approach using in vitro and in vivo electrophysiology and optogenetic manipulation of OVLT neurons. First, in vitro whole-cell patch clamp and in vivo single-unit recordings tested whether individual OVLT neurons can sense and respond to both $\mathrm{NaCl}$ and AngII. Second, in vivo optogenetic manipulations tested whether activation of rat OVLT neurons stimulated thirst and salt appetite and the extent by which OVLT neurons contribute to thirst stimulated by acute hypernatremia or elevated AngII. Rather than two anatomically distinct populations of OVLT neurons as predicted by previous Fos studies in rats (Oldfield et al., 1991, 1994; McKinley et al., 1992; Shi et al., 2008), the current experiments provide the first compelling in vivo electrophysiological evidence that a majority of OVLT neurons are responsive to both hypertonic $\mathrm{NaCl}$ and AngII stimuli and mediate thirst to both stimuli but not hypovolemia.

\section{Materials and Methods}

Animals. All of the experimental procedures conform to the National Institutes of Health Guide for the care and use of laboratory animals and were approved by the Institutional Animal Care and Use Committee at the Penn State College of Medicine or University of Pittsburgh School of Medicine. Male Sprague Dawley rats (250-400 g; Charles River Laboratories) were housed in a temperature-controlled room $\left(22 \pm 1^{\circ} \mathrm{C}\right)$ with a $12 \mathrm{~h}$ dark:light cycle (lights on at 7:00 A.M.), fed standard chow (Envigo Global Diet 2018) unless otherwise noted, and given access to deionized water.

OVLT Fos immunofluorescence to hypertonic $\mathrm{NaCl}$ or AngII. To confirm the anatomical distribution of Fos immunoreactivity to hypernatremia versus AngII within the OVLT (Oldfield et al., 1991, 1994; McKinley et al., 1992; Shi et al., 2008), rats were anesthetized with isoflurane (2\%-3\% in 100\% oxygen) and instrumented with left femoral arterial (RenaPulse 0.023 inch $\times 0.037$ inch) and venous (Silastic 0.023 inch $\times 0.037$ inch) catheters as described previously (Tucker and Stocker, 2016). All catheters were tunneled subcutaneously to exit between the scapula and an infusion harness (Covance) connected to a swivel mounted above a singlehoused urine metabolic cage. Postoperatively, animals were treated with enrofloxacin $(2 \mathrm{mg} / \mathrm{kg}$, s.c. $)$ and buprenex $(0.03 \mathrm{mg} / \mathrm{kg}$, every $12 \mathrm{~h}$ per $48 \mathrm{~h}$, s.c.). Arterial and venous catheters were flushed with heparinized saline daily (500 and $40 \mathrm{U} / \mathrm{ml}$, respectively). All experiments were performed between 10:00 A.M. and 2:00 P.M. After a $5 \mathrm{~d}$ recovery, food and water were removed at $1 \mathrm{~h}$ before experiments. Arterial blood pressure (ABP) was continuously recorded using a BPM-832 ABP monitor (CWE) and Spike2 software (Cambridge Electronic Design). After a 30 min baseline recording, animals were infused intravenously with either $2 \mathrm{M} \mathrm{NaCl}(2.5$ $\mathrm{ml}$ over $30 \mathrm{~min}$ ) or AngII ( $40 \mathrm{ng} / \mathrm{min}$ in $0.14 \mathrm{M} \mathrm{NaCl}$ at $2.5 \mathrm{ml}$ over 60 $\mathrm{min})$. Blood samples $(400 \mu \mathrm{l})$ were collected from the arterial line into microcentrifuge tubes containing heparin ( 5 units) at baseline, $35 \mathrm{~min}$ (2 $\mathrm{M} \mathrm{NaCl}$ group only), and $60 \mathrm{~min}$. Samples were centrifuged immediately $(10,000 \times g, 30 \mathrm{~s})$. Blood volume was replaced by saline for Sample 1 and then subsequently replaced by red blood cells from the previous sample resuspended in heparinized saline $(40$ units $/ \mathrm{ml})$ and warmed at $37^{\circ} \mathrm{C}$. Plasma osmolality was analyzed in duplicate by freezing point depression using a 3320 Micro Osmometer (Advanced Instruments). Plasma $\mathrm{Na}^{+}$, $\mathrm{K}^{+}$, and $\mathrm{Cl}^{-}$concentrations were measured using an EasyElectrolyte Analyzer (Medica). At 80 min after the start of the infusion, animals were animals were rapidly anesthetized with sodium Nembutal $(60 \mathrm{mg} / \mathrm{kg}$, i.v.) and perfused transcardially with saline $(50 \mathrm{ml})$ and $4 \%$ PFA $(60 \mathrm{ml})$. Brains were postfixed overnight and coronally sectioned at $40 \mu \mathrm{m}$ using a Leica Microsystems VT1000 vibratome from the diagonal band of Broca through the anterior commissure. Sections were processed for Fos immunofluorescence using a rabbit anti-c-Fos antibody $\left(1: 4000\right.$ at $4^{\circ} \mathrm{C}$ for $64 \mathrm{~h}$; RPCA-c-Fos; Encor Biotechnology) and goat-anti-rabbitAlexaFluor-594 (1:250 at room temperature for $2.5 \mathrm{~h}$; A-11012; Thermo Fisher Scientific). All incubations were performed in $10 \mathrm{~mm}$ PBS, $1 \%$ normal goat serum, and $0.1 \%$ Triton X-100 and rinsed with $10 \mathrm{~mm}$ PBS $(4 \times 6 \mathrm{~min})$ after each incubation. Sections were mounted on slides, coverslipped with Prolong Gold Antifade Mountant (16-24 h), and then imaged with a Leica Microsystems DM6000b epifluorescent microscope in Volocity 6.3 software (PerkinElmer).

In vitro electrophysiology. Whole-cell patch-clamp recordings of OVLT neurons were performed as described previously (Kinsman et al., 2017b,c). Briefly, adult male Sprague Dawley rats (250-400 g; Charles River) were anesthetized deeply with $5 \%$ isoflurane and decapitated. The brains were extracted rapidly into oxygenated $\left(95 \% \mathrm{O}_{2} / 5 \% \mathrm{CO}_{2}\right)$, icecold $\mathrm{N}$-methyl-D-glucamine (NMDG)-based aCSF (composition in $\mathrm{mm}$ as follows): $98 \mathrm{NMDG}, 2.5 \mathrm{KCl}, 1.2 \mathrm{NaH}_{2} \mathrm{PO}_{4}, 20 \mathrm{HEPES}, 91 \mathrm{HCl}, 10$ $\mathrm{MgSO}_{4}, 0.5 \mathrm{CaCl}_{2}, 25 \mathrm{NaHCO}_{3}$, and 11 D-glucose, $\mathrm{pH} 7.39$ (295 mOsm/L). Coronal slices containing OVLT were cut at $250 \mu \mathrm{m}$ thickness on a vibratome with a sapphire blade (Delaware Diamond Knives). Slices were then incubated at $33 \pm 1^{\circ} \mathrm{C}$ in oxygenated NMDG aCSF for $15 \mathrm{~min}$, then transferred to oxygenated Krebs buffer (KRB, composition in mM as follows): $126 \mathrm{NaCl}, 25 \mathrm{NaHCO}_{3}, 2.5 \mathrm{KCl}, 1.2 \mathrm{MgCl}_{2}, 2.4 \mathrm{CaCl}_{2}, 1.2$ $\mathrm{NaH}_{2} \mathrm{PO}_{4}$, and $11 \mathrm{D}$-glucose, $\mathrm{pH} 7.4(295 \mathrm{mOsm} / \mathrm{L})$ to incubate for an additional $90 \mathrm{~min}$ before cell recordings. Slices were continuously bathed in the slice chamber $(500 \mu \mathrm{l})$ by KRB supplemented with 1 mm kynurenic acid (Sigma Millipore) and $20 \mu \mathrm{m}$ bicuculline (Cayman Chemicals) via a gravity-fed perfusion system at $2-3 \mathrm{ml} \mathrm{min}^{-1}$ and warmed to $31 \pm 0.5^{\circ} \mathrm{C}$ 
with an SF-28 inline heater and TC-324B temperature controller (Warner Instruments).

Whole-cell recordings were made with borosilicate patch-pipettes pulled to resistance of 5-8 $\mathrm{m} \Omega$ when filled with potassium gluconate intracellular solution (composition in $\mathrm{mm}$ as follows): $128 \mathrm{~K}$-gluconate, $10 \mathrm{KCl}, 0.3 \mathrm{CaCl}_{2}, 1 \mathrm{MgCl}_{2}, 10 \mathrm{HEPES}, 1$ EGTA, $4 \mathrm{MgATP}, 2 \mathrm{Na}_{2}$ phosphocreatine, and $0.3 \mathrm{NaGTP}, 1.25 \mathrm{mg} / \mathrm{ml}$ Neurobiotin tracer (Vector Laboratories), and adjusted to $\mathrm{pH} 7.35$ with $\mathrm{KOH}$ and osmolarity $280 \pm$ $2 \mathrm{mOsm} / \mathrm{L}$. Data were acquired in Clampex 10.3 software with an Axopatch 200B amplifier (Molecular Devices) at a rate of $10 \mathrm{kHz}$, filtered at 2 $\mathrm{kHz}$, and digitized with a Digidata 1440A interface before being saved on a personal computer and analyzed in Clampfit 10.7 (Molecular Devices) and Spike 2.0 software. Only neuronal recordings maintaining a series resistance (i.e., pipette + access resistance) $<20 \mathrm{M} \Omega$ were considered of acceptable quality. Liquid junction potential was measured as $-12.1 \mathrm{mV}$ and was digitally corrected for post hoc in Clampfit 10.7.

Current-clamp recordings evaluated OVLT neurons that were spontaneously active when held at approximately $-55 \pm 2 \mathrm{mV}$ with current injection. Firing rates were recorded in response to baseline KRB (3-5 min, $295 \mathrm{mOsm} / \mathrm{L}$ ), $7.5 \mathrm{~mm} \mathrm{NaCl}$ (3 min, $310 \mathrm{mOsm}$ ), or 100 pм AngII (Sigma Millipore; $90 \mathrm{~s} ; 295 \mathrm{mOsm}$ ), and washout KRB (5-10 min, 295 $\mathrm{mOsm} / \mathrm{L}$ ). Neuronal responses to both $\mathrm{NaCl}$ and AngII were tested in a randomized sequence. Hypertonic $\mathrm{NaCl}$ solutions were prepared by adding $\mathrm{NaCl}$ to baseline KRB; 100 pm AngII was prepared using a 1:10,000 dilution of $1 \mu \mathrm{M}$ AngII stock aliquots added to baseline KRB. All solutions were prepared fresh daily, and solution osmolarities were measured in triplicate by freezing point depression using a 3320 Micro Osmometer (Advanced Instruments). Action potential firing rates were analyzed in Spike 2.0 software into $15 \mathrm{~s}$ bins from a continuous recording. OVLT neurons were classified as NaCl-responsive and/or AngII-responsive if the peak $1 \mathrm{~min}$ discharge exceeded the $1 \mathrm{~min}$ baseline discharge plus 2 $\mathrm{SDs}$ of the baseline discharge firing rate. One to three OVLT slices were obtained per rat, and 1 OVLT neuron was recorded per slice. Currentvoltage $(I-V)$ relationships were analyzed in voltage clamp by holding OVLT neurons at $-50 \mathrm{mV}$ and applying $400 \mathrm{~ms}$ duration, $10 \mathrm{mV}$ hyperpolarizing current steps from $-50 \mathrm{mV}$ to $-120 \mathrm{mV}$. A linear regression was derived from the $I-V$ relationship from -80 to $-50 \mathrm{mV}$. Resting membrane potential was calculated as the $\mathrm{X}$-intercept of the regression equation. Input resistance was calculated from the difference in current between -60 and $-70 \mathrm{mV}$ holding potentials.

At the end of recordings, slices were fixed in 4\% PFA for $16-20 \mathrm{~h}$, then washed with $10 \mathrm{~mm}$ PBS, pH 7.4 (PBS) $4 \times 6$ min on an orbital shaker at $100 \mathrm{rpm}$. Neurobiotin-filled cells were visualized through successive incubations in an avidin-biotin complex solution ( $1 \mathrm{~h}$, room temperature, ABC Vectastain, Vector Laboratories) and streptavidin AlexaFluor-488 conjugate (2 h, 1:250; S32354; Thermo Fisher Scientific) with PBS washes between each step. Slices were mounted on slides, coverslipped with Vectashield, and sealed with quick-drying nail polish. Neurobiotin-filled OVLT neurons were imaged using a DM6000b epifluorescent microscope (Leica Microsystems) in Volocity 6.3 software (PerkinElmer). These neurons were mapped onto neuroanatomical schematics of OVLT on three coronal planes each separated by $250 \mu \mathrm{m}$.

In vivo single-unit responses to hypertonic $\mathrm{NaCl}$ and $\mathrm{AngII}$. Rats were anesthetized with isoflurane ( $2 \%-3 \%$ in $100 \%$ oxygen) and prepared for ABP measurements (brachial artery catheter) and OVLT single-unit recordings as described previously (Kinsman et al., 2017b,c). Briefly, animals were artificially ventilated to maintain $\mathrm{P}_{\mathrm{O} 2}(35-40 \mathrm{mmHg})$ and end-tidal $\mathrm{CO}_{2}(3.5 \%-4.5 \%)$ measured continuously by a Gemini Gas Respiratory Analyzer (CWE) and corrected by adjusting ventilation rate $(60-80 \mathrm{bpm})$ or tidal volume ( $1 \mathrm{ml} / 100 \mathrm{~g}$ body weight). Body temperature was measured continuously via rectal probe (Sable Systems) and maintained at $37 \pm 0.3^{\circ} \mathrm{C}$ by a water-circulating blanket. Animals received a continuous infusion of $0.75 \% \mathrm{NaCl}$ and $0.25 \%$ glucose $(0.5$ $\mathrm{ml} / \mathrm{h}$, i.v.). After all surgical procedures were complete, isoflurane anesthesia was replaced by Inactin $(120 \mathrm{mg} / \mathrm{kg}$, i.v.). To gain access to the OVLT, the ventral surface of the hypothalamus was visualized through a ventral midline approach by removal of the hard and soft palate as described previously (Leng et al., 1991; Kinsman et al., 2017b,c). Intracarotid infusions were performed via nonocclusive catheter (heat-stretched
PE-10) inserted into the ascending pharyngeal artery and advanced 1.5 $\mathrm{mm}$ past the carotid bifurcation and into the internal carotid artery. Single-unit recordings were performed with glass electrodes $(10-25$ MOhms), filled with $4 \%$ neurobiotin (dissolved in $0.5 \%$ sodium acetate, $\mathrm{pH}$ 7.4), a micropositioner (David Kopf Instruments), and an intracellular bridge amplifier in bridge mode (Axoclamp 2B, Molecular Devices). Once a unit was identified, neuronal responses to intracarotid infusion $(50 \mu \mathrm{l})$ of $\mathrm{NaCl}(0.15$ or $0.5 \mathrm{M})$ or AngII (100 ng) were tested in a randomized order and separated by $>5 \mathrm{~min}$. All solutions were flushed through the intracarotid catheter with isotonic saline (150 $\mu$ l over $15 \mathrm{~s}$ ). Barosensitivity was tested in a subset of neurons using an aorta cuff placed around the descending aorta rostral to the renal vessels to elevate brachial $\mathrm{ABP}$ and stimulate baroreceptors. At the end of recordings, cells were juxtacellularly labeled as described previously (Pinault, 1996; Stocker and Toney, 2005; Kinsman et al., 2017c). Then, animals were perfused transcardially, and brains were postfixed overnight, sectioned at $50 \mu \mathrm{m}$, and incubated with streptavidin AlexaFluor- 488 or -594 to visualize filled cells. Discharge rates and blood pressure were averaged in $1 \mathrm{~s}$ bins. OVLT neurons were classified as responsive to a stimulus when the peak $5 \mathrm{~s}$ discharge exceeded the baseline $30 \mathrm{~s}$ discharge plus 2 SDs. The reported values for discharge and $\mathrm{ABP}$ represent the $30 \mathrm{~s}$ baseline and the peak $5 \mathrm{~s}$ response.

Thirst, salt appetite, and urinary excretion to optogenetic excitation of OVLT neurons. To test whether activation of OVLT neurons altered thirst, salt appetite, and urinary excretion, rats were anesthetized with isoflurane (2\%-3\% in 100\% oxygen) and placed into a stereotaxic frame with the skull level between bregma and lambda. The OVLT was localized by a pressor response $(>5 \mathrm{mmHg})$ to microinjection of $1 \mathrm{M} \mathrm{NaCl}(20 \mathrm{nl})$ using a femoral arterial catheter and glass micropipette $(0.68 \mathrm{~mm}$ ID, A-M Systems) angled 86 degrees from the midsagittal plane. Initial injection coordinates were $0.7 \mathrm{~mm}$ rostral to bregma and $7.5-7.8 \mathrm{~mm}$ ventral to the brain surface. The pipette was moved in $150 \mu \mathrm{m}$ increments, and injections were $>10 \mathrm{~min}$ apart. Once a pressor site was identified, the pipette was removed, rinsed with saline, and refilled to inject rAAV9CaMKIIa-hChR2(H134R)-mCherry (7.7 mm ventral; $1 \times 10^{13} \mathrm{vg} / \mathrm{ml}$, Addgene). The viral injection was performed over $10 \mathrm{~min}$ using a nitrogen-driven picopump (Toohey) and monitored using a microscope reticule in which 1 division was equal to $6 \mathrm{nl}$. At $10 \mathrm{~min}$ after the injection was complete, the pipette was removed, and a stainless-steel optic ferrule (125 $\mu \mathrm{m}$ OD, $0.22 \mathrm{NA}$; Thor Labs, CFML21L10) was implanted at 200 $\mu \mathrm{m}$ dorsal to the injection site and secured to the skull with dental cement and 4 screws. The arterial catheter was removed, incisions sutured, and animals treated with enrofloxacin $(2 \mathrm{mg} / \mathrm{kg}$, s.c.) and buprenex $(0.03$ $\mathrm{mg} / \mathrm{kg}$, s.c. every $12 \mathrm{~h}$ per $48 \mathrm{~h}$ ). Animals were returned to urine metabolic cages with access to $0.1 \% \mathrm{NaCl}$ chow (D17020, Research Diets) and water unless otherwise noted. Experiments began 2-3 weeks later.

At least $1 \mathrm{~h}$ before experiments, food was removed from the cage. A fiber optic cable ( $125 \mu \mathrm{m}$ OD, $0.22 \mathrm{NA}$; Thor Labs) was connected to the ferrule using a mating sleeve or interconnect adapter (Thor Labs). Animals were allowed to acclimate. Then, $473 \mathrm{~nm}$ light pulses (5 ms width, 8-10 $\mathrm{mW}$ confirmed post hoc at the ferrule tip, CrystaLaser CL473$075-\mathrm{O})$ were applied at various frequencies $(1,5,10$, and $20 \mathrm{~Hz}, 50 \%$ duty cycle $2 \mathrm{~s}$ ON to $2 \mathrm{~s}$ OFF) and triggered by a 1401 and Spike2 software (Cambridge Electronic Design) for a duration of $30 \mathrm{~min}$. A single frequency was tested per day in randomized order. Cumulative water intake and urine output were recorded every $15 \mathrm{~min}$. Latency to drink was recorded using a lickometer constructed by connecting two wires to the floor of the metabolic cage and metal spout of the drinking tube. To test whether the behavior was phase-locked to the light pulses, one additional test was performed in which $473 \mathrm{~nm}$ light pulses were applied as described above at $20 \mathrm{~Hz}$, but the duration was $5 \mathrm{~min}$ versus $30 \mathrm{~min}$. Finally, to test whether optogenetic activation of OVLT neurons stimulated salt appetite, rats were given access to $0.01 \% \mathrm{NaCl}$ diet (D17010, Research Diets), distilled water, and $0.3 \mathrm{M} \mathrm{NaCl}$ for 1 week after thirst experiments were complete. Then, $473 \mathrm{~nm}$ laser pulses were applied at various frequencies as described above. Water intake, $0.3 \mathrm{M} \mathrm{NaCl}$ intake, and urine output were recorded as described above.

At the end of experiments, a subset of animals $(n=4)$ were anesthetized and prepared for OVLT single-unit recordings as described above. 
OVLT neurons were identified by anatomical location and discharge response to intracarotid infusion of $0.5 \mathrm{M} \mathrm{NaCl}(50 \mu \mathrm{l})$ as described above. To verify that light pulses triggered action potential discharge in OVLT neurons, 473 $\mathrm{nm}$ light pulses ( $5 \mathrm{~ms}$ width, $8-10 \mathrm{~mW}$, CrystaLaser CL473-075-O) were applied at various frequencies $(1,5,10$, and $20 \mathrm{~Hz}, 50 \%$ duty cycle $1 \mathrm{~s}$ train, 1401 and Spike2 software, Cambridge Electronic Design) for a duration of 1-5 min at each frequency. Neurons were juxtacellularly labeled to confirm location and visualized as described above. At the end of all experiments, the animals were deeply anesthetized with $4 \%$ isoflurane and perfused transcardially as described above. Brains were postfixed overnight, immersed in 30\% sucrose, and sectioned at 50 $\mu \mathrm{m}$. Immunofluorescence and the optical ferrule tract were imaged using a DM6000b epif-

luorescent microscope (Leica Microsystems) in Volocity 6.3 software (PerkinElmer). Injection sites were mapped onto neuroanatomical schematics of OVLT on three coronal planes each separated by $200 \mu \mathrm{m}$.

Thirst responses to hypertonic $\mathrm{NaCl}$ and hypotension during optogenetic inhibition of OVLT neurons. To test whether OVLT neurons contributed to thirst stimulated by $\mathrm{NaCl}$ or AngII, a final set of experiments measured water intake and urine output in response to intravenous infusion of hypertonic saline or diazoxide-induced hypotension while OVLT neurons were inhibited optogenetically. Since intravenous infusion of AngII does not produce a powerful dipsogenic response due to the concomitant increased ABP (Robinson and Evered, 1987; Stocker et al., 2002), the vasodilator diazoxide was used to produce hypotension. Hypotensioninduced thirst depends on circulating AngII levels (Evered, 1990; Stocker et al., 2003). Rats were anesthetized as described above, the OVLT localized by a pressor response to $1.0 \mathrm{M} \mathrm{NaCl}$, and rAA2-CaMKIIa-eNpHr3.0mCherry (60 nl at $7.7 \mathrm{~mm}$ ventral, $1 \times 10^{12}$ particles/ml, UNC Vector Core). The pipette was removed, and an optical ferrule ( $125 \mu \mathrm{m}$ OD, 0.22 NA; Thor Labs) was implanted at $200 \mu \mathrm{m}$ dorsal to the injection site and secured to the skull with 4 screws and dental cement. The arterial catheter removed, incisions sutured, and animals treated with enrofloxacin (2 $\mathrm{mg} / \mathrm{kg}$, s.c.) and buprenex (0.03 mg/kg, s.c. every $12 \mathrm{~h}$ per $48 \mathrm{~h})$. Animals were returned to urine metabolic cages with access to $0.1 \% \mathrm{NaCl}$ (D17020, Research Diets) and water for a 2 to 3 week recovery.

Then, animals were anesthetized with isoflurane and instrumented with arterial and venous catheters as described above and given $4 \mathrm{~d}$ to recover. At least $1 \mathrm{~h}$ before experiments began, food was removed from cages. The ferrule was connected to a fiber optic cable and $561 \mathrm{~nm}$ laser (CL561-075-O, CrystaLaser). Animals received an intravenous infusion of $2 \mathrm{M} \mathrm{NaCl}(2.5 \mathrm{ml}$ per $30 \mathrm{~min})$ or bolus injection of diazoxide $(25 \mathrm{mg} / \mathrm{kg}$, i.v.). A continuous light $(8 \mathrm{~mW})$ or $20 \mathrm{~Hz}(8 \mathrm{~mW}, 5 \mathrm{~ms}$ pulse, $2 \mathrm{~s} \mathrm{ON}$ to 2 s OFF, $50 \%$ duty cycle) was applied for $30 \mathrm{~min}$ and started at the time of the infusion or bolus injection. The control condition consisted of the same experimental paradigm, but the laser was not turned on. Each animal received all treatments (hypertonic $\mathrm{NaCl}$ or diazoxide) with or without the laser on in a randomized order. Cumulative water intake and urine output were measured every $15 \mathrm{~min}$. Latency to drink was also recorded using a lickometer and Spike2 software (Cambridge Electronic Design). At the end of experiments, animals were anesthetized and perfused transcardially to harvest brains and analyzed mCherry expression as described above.

To test whether optogenetic inhibition of OVLT neurons reduced water intake to stimuli independent of hypernatremia or Ang II, a separate group of animals received an injection of rAA2-CaMKIIa-eNpHr3.0mCherry $\left(60 \mathrm{nl}\right.$ at $7.7 \mathrm{~mm}$ ventral, $1 \times 10^{12}$ particles/ml, UNC Vector Core) and optical ferrule targeted at the OVLT as described above. Animals were singly house in metabolic cages for 4 weeks. Then, animals were briefly anesthetized with isoflurane $\left(2 \%-3 \%\right.$ in $\left.100 \% \mathrm{O}_{2}\right)$ and received an injection of $20 \%(\mathrm{w} / \mathrm{w})$ polyethylene glycol (PEG, $5 \mathrm{ml}$, s.c., $20,000 \mathrm{MW}$ ). The ferrule was connected to the fiber optic cable as described above, and animals were returned to home cages without access to water for $5 \mathrm{~h}$. A continuous light $(\mathrm{ON}, 8 \mathrm{~mW})$ or no light was applied at $5 \mathrm{~min}$ before access to water and $30 \mathrm{~min}$ thereafter. The order of treatment was randomized and separated by $7 \mathrm{~d}$. Water intake, urine output, and latency to drink were recorded as described above.

Statistical analysis. The number of rats, brain slices, and neurons per group and experiment are provided in the respective Results section and figure legends. All data are presented as mean \pm SEM plus individual data points when possible. $p<0.05$ was statistically significant for all comparisons. Fos experiments: $\mathrm{ABP}$ and heart rate were averaged in 5 min bins and analyzed by a two-way ANOVA with repeated measures. When significant $F$ values were obtained, paired $t$ tests with layered Bonferroni correction were performed to compare with baseline values. Plasma electrolytes and osmolality were analyzed similarly using paired or independent $t$ tests with a layered Bonferroni correction. In vitro patch-clamp recordings: Discharge rates were analyzed within each response group ( $\mathrm{NaCl}+$ AngII, $\mathrm{NaCl}$ only, AngII only, or nonresponsive) by paired $t$ tests. The effect of stimulus application sequence on discharge rate for the $\mathrm{NaCl}+$ AngII group was assessed using a two-way ANOVA with repeated measures. In vivo single-unit recordings: Discharge rate and ABP within each group were analyzed by paired $t$ tests. Differences in baseline firing rates across groups were analyzed by a one-way ANOVA. Thirst and salt appetite: Water intake was analyzed by one-way or twoway ANOVA with repeated measures. When significant $F$ values were obtained, post hoc test was performed using paired $t$ tests with layered Bonferroni correction, independent $t$ tests with layered Bonferroni correction, or a Fisher's LSD (three groups). Thirty minute water intake and latencies to drink were analyzed similarly. All statistical tests were performed using Sigma Plot (11.0) or Systat (10.2) software.

\section{Results}

Hypertonic $\mathrm{NaCl}$ versus AngII produce different patterns of Fos immunoreactivity in the OVLT

intravenous infusion of hypertonic $2 \mathrm{M} \mathrm{NaCl}(n=3)$ and 40 $\mathrm{ng} / \mathrm{min}$ AngII $(n=3)$ evoked qualitatively distinct patterns of Fos immunoreactivity across the rostrocaudal extent of OVLT. Hypertonic $\mathrm{NaCl}$ produced Fos-labeled cells within the dorsal cap and lateral margins throughout the rostrocadual extent (Fig. 1A). However, few Fos-labeled cells were present in the vascular core. In marked contrast, AngII infusion produced dense Fos immunoreactivity in the vascular core but little in the dorsal cap or lateral margins (Fig. 1A). Both treatments significantly increased mean ABP from baseline levels (Fig. $1 B ; F_{(6,24)}=29.04, p=$ 0.0032 ANOVA) and decreased HR $\sim 50 \mathrm{bpm}$ from baseline values (NaCl: $321 \pm 9$ bpm and AngII: $310 \pm 6$ bpm; $F_{(6,24)}=5.39$, $p=0.0258$ ANOVA). Hypertonic $\mathrm{NaCl}$ increased plasma osmolality $\left(F_{(2,4)}=30.3, p=0.0231\right.$, ANOVA $)$, plasma $\left[\mathrm{Na}^{+}\right]\left(F_{(2,4)}=\right.$ $52.8, p=0.0183$, ANOVA $)$, and plasma $\left[\mathrm{Cl}^{-}\right]\left(F_{(2,4)}=85.3, p=\right.$ 0.0019, ANOVA) (Fig. 1B). However, AngII infusion decreased 
A

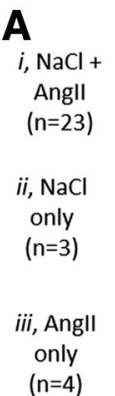

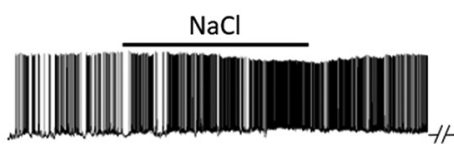
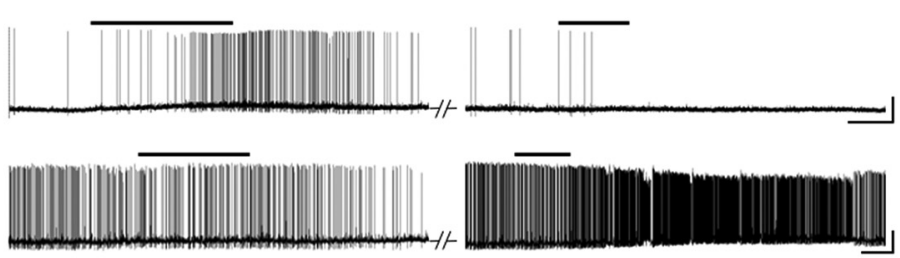

iv, Non$(n=3)$
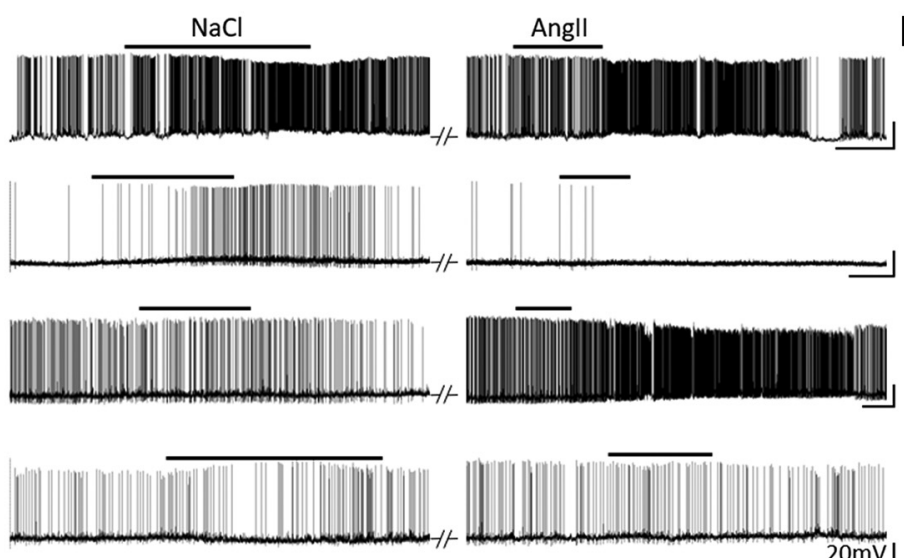

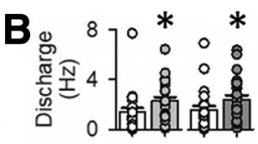
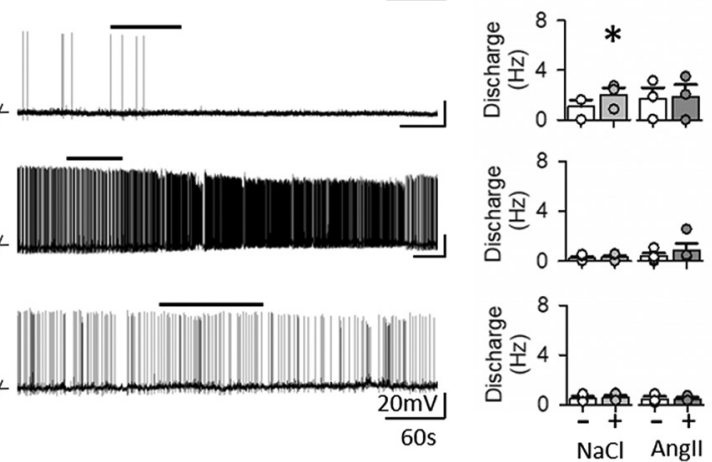

Figure 2. In vitro current-clamp responses of OVLT neurons to hypertonic NaCl and Angll. $A$, Current-clamp traces of OVLT neurons held at approximately $-55 \mathrm{mV}$ in response to bath application of hypertonic $\mathrm{NaCl}(7.5 \mathrm{~mm})$ and Angll (100 pM). B, Mean \pm SEM and individual data points for discharge rates before $(-)$ and the final 1 min $(+)$ of hypertonic NaCl or Angll. OVLT neurons were classified as (Ai) coresponsive (23 neurons/23 slices/19 rats), (Aii) responsive to NaCl only (3 neurons/3 slices/2 rats), (Aiii) responsive to Angll only ( 4 neurons/4 slices/4 rats), or (Aiv) nonresponsive (3 neurons/3 slices/3 rats). Responsiveness was defined as an increase in AP firing rate $\geq 2 \sigma$ above baseline in response to stimulus bath application. The majority of OVLT neurons are coresponsive to hyperosmotic $\mathrm{NaCl}$ and Angll. ${ }^{*} p<0.0001$ versus baseline (paired $t$ test).

plasma osmolality $\left(t_{(2)}=5.20, p=0.035\right.$, paired $t$ test $)$ but did not change plasma $\left[\mathrm{Na}^{+}\right]\left(t_{(2)}=1.27, p=0.331\right.$, paired $t$ test $)$ or plasma $\left[\mathrm{Cl}^{-}\right]\left(t_{(2)}=1.41, p=0.294\right.$, paired $t$ test) (Fig. $\left.1 B\right)$.

\section{Hypertonic $\mathrm{NaCl}$ and AngII excite overlapping populations of OVLT neurons in vitro}

To evaluate the extent by which hypertonic $\mathrm{NaCl}$ and AngII affect overlapping versus distinct populations of OVLT neurons, whole-cell patch-clamp recordings were performed to assess responses to bath-applied $\mathrm{NaCl}$ (7.5 mM) or AngII (100 pM) during blockade of ionotropic glutamatergic and GABAergic neurotransmission. A total of 35 OVLT neurons were recorded from 26 rats. Of the OVLT neurons tested, $66 \%$ ( 23 of 35 ) demonstrated an increased discharge to both hypertonic $\mathrm{NaCl}\left(1.1 \pm 0.2\right.$ to $2.2 \pm 0.3 \mathrm{~Hz}$; $t_{(22)}=$ $-6.186, p=0.000$, paired $t$ test $)$ and AngII ( $1.3 \pm 0.4$ to $2.2 \pm 0.3$ $\mathrm{Hz} ; t_{(22)}=-6.99, p=0.000$, paired $t$ test) (Fig. $\left.2 A i, B\right)$. No significant difference was observed in discharge responses between coresponsive OVLT neurons on the basis of the stimulus bath application sequence $\left(\right.$ AngII $\rightarrow \mathrm{NaCl}$ vs $\mathrm{NaCl} \rightarrow$ AngII; $F_{(1,63)}=$ $0.609, p=0.444$, sequence effect, two-way repeated-measures ANOVA). Two coresponsive neurons were excluded from the analysis above in which hypertonic $\mathrm{NaCl}$ decreased the discharge of both neurons but AngII increased the discharge rate of one neuron but decreased the discharge rate of the other.

Fewer OVLT neurons were responsive to either hypertonic $\mathrm{NaCl}$ or AngII alone. For instance, 9\% (3 of 35) of OVLT neurons increased discharge in response to hypertonic $\mathrm{NaCl}(1.08 \pm 0.53$ to $2.01 \pm 0.58 \mathrm{~Hz} ; t_{(2)}=-9.773, p=0.01$, paired $t$ test) but not to AngII ( $1.69 \pm 0.90$ to $1.85 \pm 0.99 \mathrm{~Hz} ; t_{(2)}=-1.395, p=0.298$, paired $t$ test) (Fig. 2Aii,B). Conversely, $11 \%$ (4 of 35) of OVLT neurons increased discharge in response to AngII $(0.38 \pm 0.24$ to $0.92 \pm 0.54 \mathrm{~Hz} ; t_{(3)}=-1.731, p=0.182$, paired $t$ test) but not hypertonic $\mathrm{NaCl}\left(0.23 \pm 0.13\right.$ to $0.27 \pm 0.16 \mathrm{~Hz} ; t_{(3)}=-1.252$, $p=0.299$, paired $t$ test) (Fig. 2Aiii, B). Last, 9\% (3 of 35) of OVLT neurons did not respond to either hypertonic $\mathrm{NaCl}(0.50 \pm 0.19$ to $0.57 \pm 0.18 \mathrm{~Hz} ; t_{(2)}=-2.00, p=0.183$, paired $t$ test) or AngII $\left(0.48 \pm 0.21\right.$ to $0.48 \pm 0.13 \mathrm{~Hz} ; t_{(2)}=-0.072, p=0.949$, paired $t$ test) (Fig. 2Aiv, B).

The proportion of OVLT neurons responsive to $\mathrm{NaCl}$ versus AngII between response categories was not biased by the se-

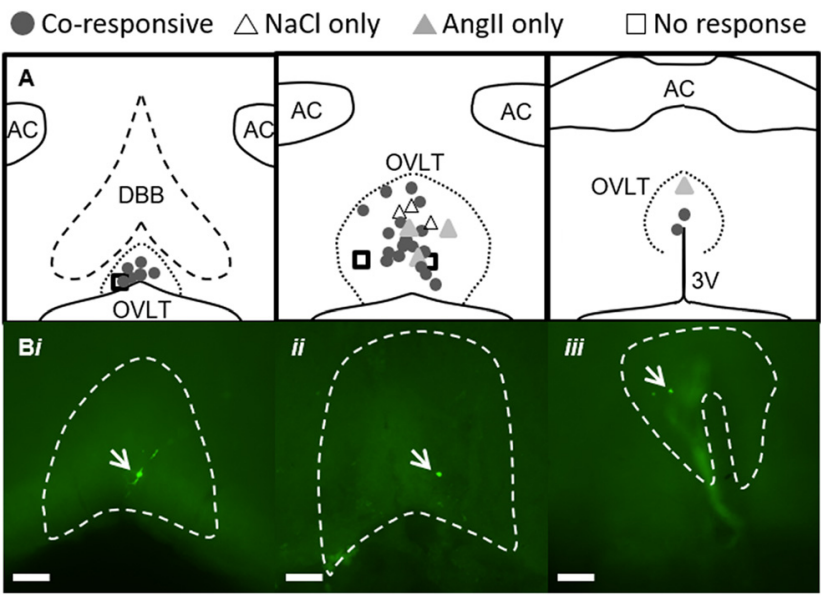

Figure 3. Neuroanatomical map of OVLT neuron responses to hypertonic $\mathrm{NaCl}$ and Angll in vitro. $\boldsymbol{A}$, Schematic illustration of three rostrocaudal levels and anatomical location of OVLT neurons recorded in vitro and presented in Figure 2. B. Examples of neurobiotin-labeled and coresponsive neurons (green, indicated with white arrows) at three different anatomical locations within OVLT: (Bi) rostromedial, (Bii) lateral margin, (Biii) dorsal cap. Scale bars, $100 \mu \mathrm{m}$ (10X images).

quence of stimulus application $\left(\chi_{(3)}^{2}=1.681, p=0.641, \chi^{2}\right)$. In addition, no significant differences were observed between response groups on the basis of input resistance (in $\mathrm{M} \Omega ; \mathrm{NaCl}+$ AngII: $1911 \pm$ 275; NaCl: $1312 \pm 321$; AngII: $1405 \pm 173$; nonresponsive: $2540 \pm 1476 ; \mathrm{H}_{(3)}=0.335, p=0.953$, Kruskal-Wallis one-way ANOVA on ranks) or resting membrane potential (in $\mathrm{mV}$; $\mathrm{NaCl}+$ AngII: $-56.5 \pm 2.2$; NaCl: $-60.3 \pm 2.5$; mannitol: $-60.7 \pm 2.5$; nonresponsive: $-63.1 \pm 3.9 ; \mathrm{H}_{(3)}=2.885, p=$ 0.410 , Kruskal-Wallis one-way ANOVA on ranks).

Post hoc immunofluorescent identification of neurobiotinfilled OVLT neurons revealed that $\mathrm{NaCl}+\mathrm{AngII}, \mathrm{NaCl}$ only, AngII only, and nonresponsive OVLT neurons were distributed throughout all rostrocaudal levels of OVLT (Fig. 3). However, the majority of OVLT neurons coresponsive to both hypertonic $\mathrm{NaCl}$ and AngII were located nearest the dorsal region of the vascular core (Fig. 3). 
The majority of OVLT neurons respond to hypertonic $\mathrm{NaCl}$ and $\mathrm{AngII}$ in vivo A parallel set of experiments was performed in vivo to assess the extent by which OVLT neurons respond to both hypertonic $\mathrm{NaCl}$ and AngII. Single-unit recordings of 44 OVLT neurons were performed in 23 anesthetized rats. Baseline mean $\mathrm{ABP}$ and heart rate were $104 \pm$ $3 \mathrm{mmHg}$ and $397 \pm 6 \mathrm{bpm}$, respectively. Figure 4 illustrates examples of neurons responsive to intracarotid injection of hypertonic $\mathrm{NaCl}$ and AngII, hypertonic $\mathrm{NaCl}$ only, or AngII only. Figure 5 illustrates summary data. The majority of OVLT neurons $(52 \%, 23$ of 44) demonstrated an increase in discharge to intracarotid injection of both hypertonic $\mathrm{NaCl}$ $\left(2.8 \pm 0.6\right.$ to $7.5 \pm 1.1 \mathrm{~Hz} ; t_{(22)}=-7.030$, $p=0.000$, paired $t$ test $)$ and AngII (3.1 \pm 0.7 to $9.2 \pm 1.5 \mathrm{~Hz} ; t_{(22)}=-5.791, p=$ 0.000 , paired $t$ test). Since mean ABP significantly increased during injection of hypertonic $\mathrm{NaCl}(104 \pm 4$ to $115 \pm 4$ $\mathrm{mmHg} ; t_{(22)}=-5.750, p=0.000$, paired $t$ test $)$ and AngII $(107 \pm 4$ to $147 \pm 4$ $\mathrm{mmHg} ; t_{(22)}=-17.344, p=0.000$, paired $t$ test), barosensitivity was tested in a subset of these neurons $(n=12)$. Inflation of an aortic cuff for $30 \mathrm{~s}$ increased mean $\mathrm{ABP}(92 \pm 6$ to $122 \pm 7 \mathrm{mmHg}$; $t_{(11)}=-8.481, p=0.000$, paired $t$ test $)$ but did not alter discharge $(3.9 \pm 1.1$ to $4.1 \pm 1.1 \mathrm{~Hz} ; t_{(11)}=-0.903, p=0.386$, paired $t$ test). Last, intracarotid injection of isotonic saline did not alter cell discharge $\left(3.1 \pm 0.7\right.$ to $3.3 \pm 0.7 \mathrm{~Hz}$; $t_{(22)}=$ $-1.166, p=0.256$, paired $t$ test) or mean $\operatorname{ABP}\left(104 \pm 4\right.$ to $104 \pm 4 \mathrm{mmHg} ; t_{(22)}=$ $-0.894, p=0.381$, paired $t$ test $)$.

A smaller proportion of OVLT neurons responded to either hypertonic $\mathrm{NaCl}$ or AngII alone. Approximately 14\% (6 of 44) of OVLT neurons displayed an increase in discharge to intracarotid hypertonic $\mathrm{NaCl}(4.3 \pm 1.9$ to $10.0 \pm 3.3 \mathrm{~Hz}$; $t_{(5)}=-3.648, p=0.0148$, paired $t$ test) but not AngII ( $4.5 \pm 1.8$ to $3.8 \pm 1.5 \mathrm{~Hz}$; $t_{(5)}=0.897, p=0.411$, paired $t$ test) or isotonic $\mathrm{NaCl}(4.4 \pm 1.8$ to $4.7 \pm 1.9 \mathrm{~Hz}$; $t_{(5)}=-1.778, p=0.136$, paired $t$ test). On the other hand, $16 \%$ ( 7 of 44) of OVLT neurons had an increased discharge to AngII $\left(2.5 \pm 0.6\right.$ to $7.0 \pm 1.3 \mathrm{~Hz} ; t_{(6)}=-4.191, p=0.006$, paired $t$ test $)$ but not hypertonic $\mathrm{NaCl}\left(2.6 \pm 0.6\right.$ to $2.5 \pm 0.5 \mathrm{~Hz} ; t_{(6)}=0.996$, $p=0.358$, paired $t$ test $)$ or isotonic $\mathrm{NaCl}(2.5 \pm 0.6$ to $2.6 \pm 0.6$ $\mathrm{Hz} ; t_{(6)}=-1.461, p=0.194$, paired $t$ test). Approximately $18 \%$ (8 of 44) of OVLT neurons were unresponsive and did not alter cell discharge to isotonic $\mathrm{NaCl}\left(1.1 \pm 0.3\right.$ to $1.1 \pm 0.4 \mathrm{~Hz} ; t_{(7)}=$ $-0.281, p=787$, paired $t$ test), hypertonic $\mathrm{NaCl}(1.2 \pm 0.4$ to $1.2 \pm 0.3 \mathrm{~Hz} ; t_{(7)}=-0.682, p=0.682$, paired $t$ test), or AngII $\left(0.9 \pm 0.3\right.$ to $1.0 \pm 0.3 \mathrm{~Hz} ; t_{(7)}=-0.565, p=0.589$, paired $t$ test $)$. In these neurons ( $\mathrm{NaCl}$ only, AngII only, and unresponsive), mean $\mathrm{ABP}$ increased in response to injection of hypertonic $\mathrm{NaCl}$ A

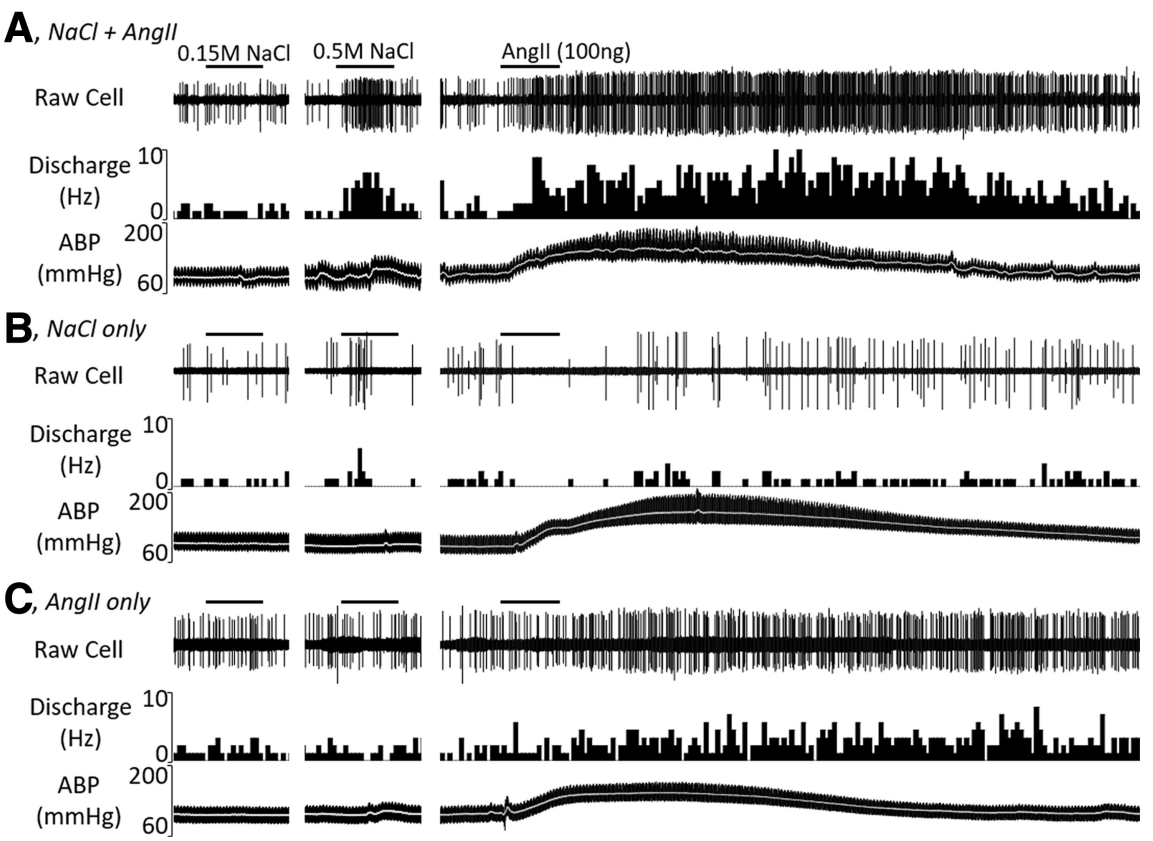

Figure 4. Example of raw cell discharge, ratemeter histogram, and ABP for OVLT neurons during intracarotid injection of $(\boldsymbol{A})$ $0.15 \mathrm{M} \mathrm{NaCl},(\boldsymbol{B}) 0.5 \mathrm{~m} \mathrm{NaCl}(50 \mu \mathrm{l})$, and (C) Angll (100 ng). Summary data are presented in Figure 5. Each solution (50 $\mu \mathrm{l})$ was

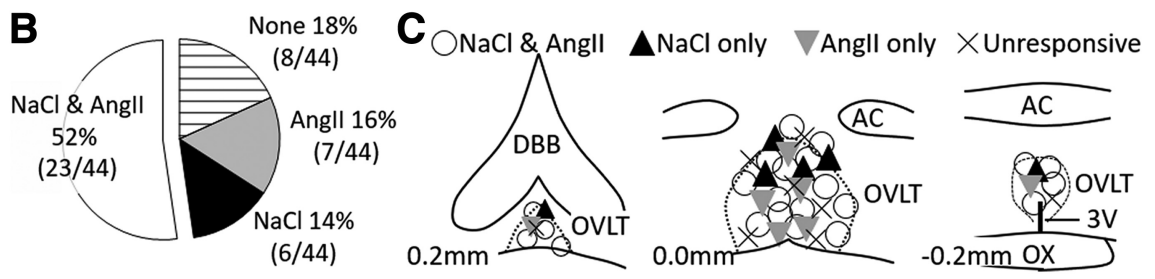

Figure 5. $\quad \boldsymbol{A}$, Mean \pm SEM and individual data points of cell discharge before and during intracarotid injection of $0.15 \mathrm{M} \mathrm{NaCl}, 0.5$ $\mathrm{M} \mathrm{NaCl}$, and $100 \mathrm{ng}$ Angll in four classes of OVLT neurons: $\mathrm{NaCl}$ and Angll, NaCl only, Angll only, and unresponsive. Neurons were classified into these categories based on a peak $5 \mathrm{~s}$ discharge response $>2$ SDs from the mean. ${ }^{*} p<0.05$ versus baseline (paired $t$ tests). $\boldsymbol{B}$, Pie chart illustrating proportion of OVLT neurons in different responses profiles. C, Schematic illustration of OVLT neurons at three different rostrocaudal levels in the OVLT.

$\left(106 \pm 4\right.$ to $114 \pm 4 \mathrm{mmHg} ; t_{(20)}=-4.124, p=0.001$, paired $t$ test) and AngII (107 \pm 4 to $148 \pm 4 \mathrm{mmHg} ; t_{(20)}=-17.827, p=$ 0.000 , paired $t$ test). Thus, barosensitivity was tested again in a subset of neurons $(n=9)$. Although inflation of an aortic cuff significantly increased $\mathrm{ABP}\left(99 \pm 4\right.$ to $122 \pm 4 \mathrm{mmHg} ; t_{(8)}=$ $-10.982, p=0.000$, paired $t$ test $)$, cell discharge was not significantly different $\left(3.0 \pm 1.2\right.$ to $3.2 \pm 1.3 \mathrm{mmHg} ; t_{(8)}=-1.397, p=$ 0.200 , paired $t$ test). One neuron was excluded from this barosensitivity analysis as inflation of an aortic cuff increased mean ABP (112 to $143 \mathrm{mmHg}$ ) and cell discharge (3.1 to $8.2 \mathrm{~Hz}$ ).

No significant differences were observed in baseline firing rates between the response profile of the neurons (Fig. $5 A ; F_{(3,40)}=$ $1.564, p=0.213$, one-way ANOVA). Juxtacellular labeling of 
A, In vivo OVLT single-unit recording
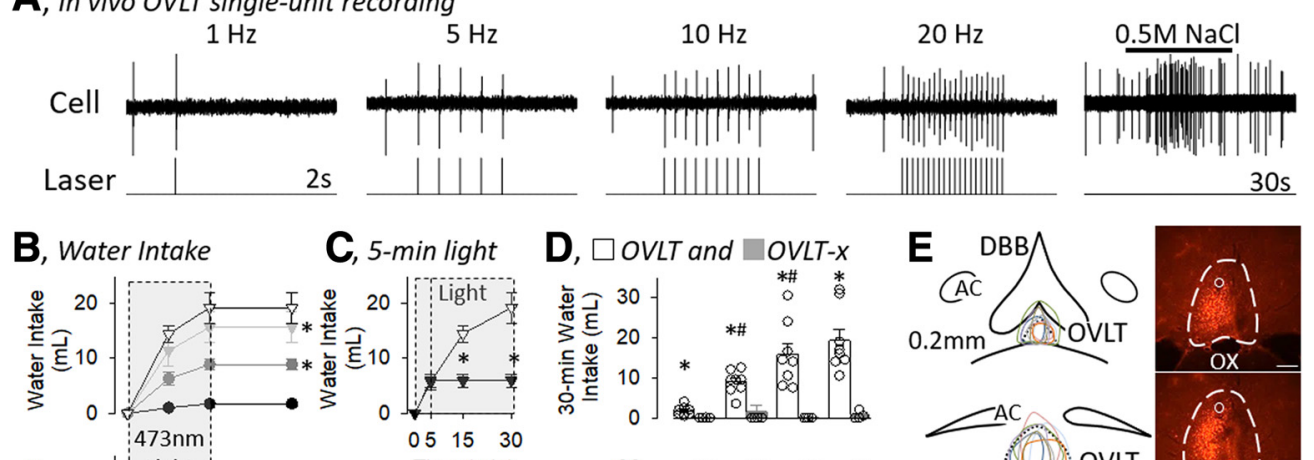

C, 5-min light

D, $\square$ OVLT and $\square O V L T-x$
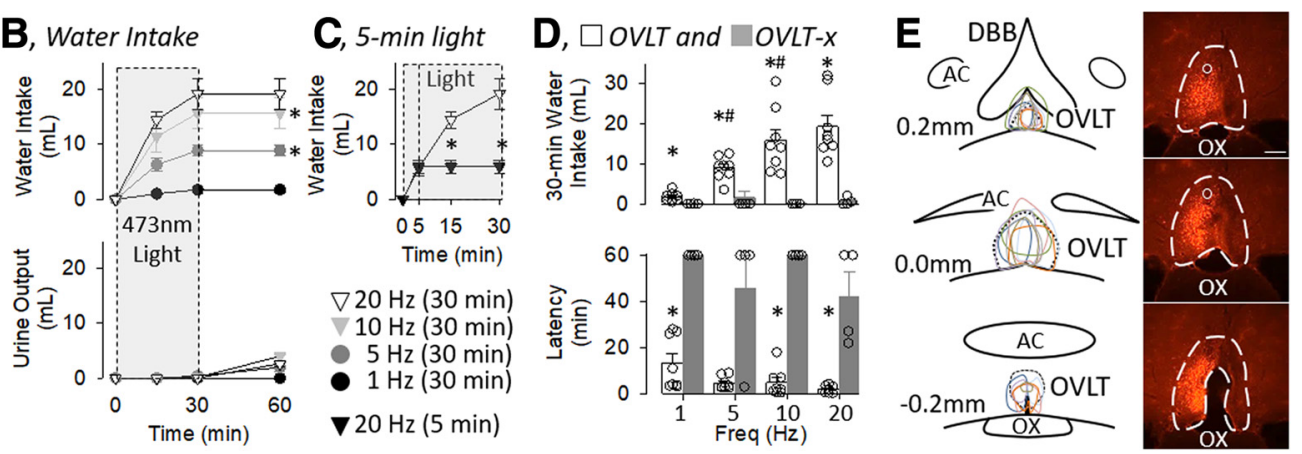

Figure 6. A, In vivo single-unit recording for an OVLT neuron during optogenetic stimulation of $473 \mathrm{~nm}$ light pulses ( $5 \mathrm{~ms}$ pulse, $1 \mathrm{~s}$ train) at various frequencies. Light pulses produced an immediate and 1:1 light/action potential response. Intracarotid infusion of $0.5 \mathrm{~m} \mathrm{NaCl}$ illustrates an NaCl-responsive OVLT neuron. $\boldsymbol{B}$, Mean \pm SEM of cumulative water intake and urine output of rats $(n=8)$ during optogenetic stimulation ( $5 \mathrm{~ms}$ pulse, $50 \%$ duty cycle, $30 \mathrm{~min}$ ) of $0 \mathrm{VLT}$ neurons at various frequencies $(1,5,10$, and $20 \mathrm{~Hz})$. Gray box represents when light was applied. ${ }^{*} p<0.05$ versus next lower frequency (for ANOVA values, see text). C, Five minute optogenetic stimulation increased water intake during the initial 5 min, but no rats ingested water over the next 55 min after the light was turned off. Rats with 30 min optogenetic stimulation were replotted here for comparison. ${ }^{*} p<0.05,5$ min versus 30 min ( $t$ test). $D$, Mean \pm SEM and data points of rats with ( $0 V L T$, $n=8$ ) or without (OVLT-x, $n=4)$ mCherry expression and an optical ferrule in the OVLT. ${ }^{*} p<0.05,0$ VLT versus OVLT-x (layered Bonferroni with correction; for ANOVA, see text). ${ }^{\#} p<0.05$ versus lower frequency (paired $t$ tests with layered Bonferroni correction) (for ANOVA, see text). E, Schematic illustration of mCherry expression for 8 OVLT rats and digital image of representative $m C h e r r y$ expression and tip of optical ferrule (0). Scare bar, $200 \mu \mathrm{m}$.

recorded neurons provided an anatomical map of OVLT neurons. Figure $5 C$ illustrates the location of OVLT neurons. OVLT neurons responsive to hypertonic $\mathrm{NaCl}$ and AngII were distributed throughout the vascular core, dorsal cap, and lateral margins. Other cell populations were distributed through the rostrocaudal extent of OVLT without a clear anatomical distribution based on the response profile.

\section{Optogenetic excitation of OVLT neurons stimulates thirst but} not salt appetite

To determine whether selective and direct excitation of OVLT neurons stimulates thirst and salt appetite in rats, OVLT neurons were activated optogenetically using a CaMKIIa promoter and various frequencies. Figure $6 \mathrm{~A}$ illustrates a single-unit recording of an OVLT neuron in which $5 \mathrm{~ms}$ laser $473 \mathrm{~nm}$ pulses at various frequencies produced an action potential phase-locked to the light stimulus in a 1:1 light/action potential manner. It is noteworthy that, when the pulse duration was increased from 5 to 10 $\mathrm{ms}$, a single light pulse evoked 2 action potentials in $\sim 50 \%$ of the trials (data not shown). This was rarely observed when a $5 \mathrm{~ms}$ pulse duration was used. As expected, intracarotid injection of $0.5 \mathrm{M} \mathrm{NaCl}(50 \mu \mathrm{l})$ increased the discharge rate of this cell.

Optogenetic stimulation of OVLT neurons in conscious animals for $30 \mathrm{~min}$ produced a frequency-dependent increase in water intake (Fig. 6B). Rats typically were asleep when the laser pulses began, woke up, and began to drink within the initial $5 \mathrm{~min}$. A

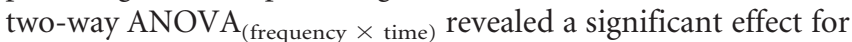
frequency $\left(F_{(3,28)}=12.561, p=0.00\right)$, time $\left(F_{(3,84)}=93.663, p=\right.$ $0.000)$, and interaction $\left(F_{(9,84)}=11.154, p=0.000\right)$. A significant main effect for frequency was observed at $15 \mathrm{~min}\left(F_{(3,28)}=\right.$ 8.8493, $p=0.000), 30 \mathrm{~min}\left(F_{(3,28)}=11.730, p=0.000\right)$, and 60 $\min \left(F_{(3,28)}=14.008, p=0.000\right)$. Post hoc analyses indicated that water intake at 30 and 60 min was significantly greater between 5 versus $1 \mathrm{~Hz}$ and 10 versus $5 \mathrm{~Hz}$, but no statistical difference was present between 10 versus $20 \mathrm{~Hz}$ (Fig. 6B). Despite the increase in water intake over the $30 \mathrm{~min}$ of optogenetic stimulation, only 1 animal excreted any urine during the initial $30 \mathrm{~min}$ at any frequency $(1 \mathrm{ml}$ at $10 \mathrm{~Hz}$ trial). Analysis of urine volumes at $60 \mathrm{~min}$ indicated a significant effect $\left(F_{(3,28)}=6.570, p=0.002\right.$ ANOVA $)$. However, post hoc testing ( $t$ test with layered Bonferroni correction) did not reveal a frequency-dependent effect ( $1 \mathrm{vs} 5 \mathrm{~Hz}, 5 \mathrm{vs}$ $10 \mathrm{~Hz}$, or 10 vs $20 \mathrm{~Hz}$ ). This resulted in a frequency-dependent increase in water balance at $60 \mathrm{~min}(1 \mathrm{~Hz}: 1.8 \pm 0.4 \mathrm{ml}$ vs $5 \mathrm{~Hz}$ : $6.9 \pm 1.0 \mathrm{ml}$ vs $10 \mathrm{~Hz}: 11.8 \pm 2.6 \mathrm{ml}$ vs $20 \mathrm{~Hz}: 16.7 \pm 3.0 \mathrm{ml}$; $F_{(3,28)}=9.766, p=0.000$ ANOVA).

Two additional experiments were performed to test the dependence and specificity on the light-induced stimulation of OVLT neurons. First, a final trial was performed in the same animals, but $20 \mathrm{~Hz}$ light stimulation was applied for $5 \mathrm{~min}$. All 8 rats drank water during the initial $5 \mathrm{~min}$; however, when the light was turned off at $5 \mathrm{~min}$, no rats continued to ingest any water for the next 55 min (Fig. 6C). Last, 4 additional rats, in which mCherry expression was not detected or outside the OVLT, served as an anatomical and experimental control group. Figure $6 \mathrm{D}$ illustrates cumulative $30 \mathrm{~min}$ water intakes and latencies to the first lick for rats with (OVLT) or without (OVLT-x) mCherry expression and an optical ferrule. A two-way ANOVA (group, frequency) of $30 \mathrm{~min}$ water intakes indicated a significant effect of group $\left(F_{(1,10)}=\right.$ $28.852, p=0.000)$, frequency $\left(F_{(3,30)}=8.878, p=0.000\right)$, and interaction $\left(F_{(3,10)}=8.657, p=0.000\right)$. OVLT versus OVLT-x rats ingested more water at every frequency (Fig. $6 D$ ). In addition, a two-way ANOVA (group, frequency) cated a significant effect of group $\left(F_{(1,10)}=35.050, p=0.000\right)$, frequency $\left(F_{(3,30)}=3.2446, p=0.03566\right)$, but no interaction $\left(F_{(3,10)}=0.878, p=0.465\right)$. OVLT rats displayed a shorter latency to drink versus OVLT-x rats (Fig. 6D). It is noteworthy that the majority of OVLT-x rats did not drink during the trials.

Figure $6 E$ illustrates a schematic diagram of injection sites throughout the rostrocaudal extent of the OVLT accompanied by a representative example of mCherry expression. mCherry ex- 
pression did not extend dorsally into the median preoptic nucleus, rarely extended rostrally into the diagonal band of Broca, and stopped caudally within $200 \mu \mathrm{m}$ at the start of the third ventricle. It is noteworthy that preliminary experiments used much larger injection volumes $(250 \mathrm{nl}$ injection at 1 site or $150 \mathrm{nl}$ at 2 sites separated by $200 \mu \mathrm{m}$ ) and produced expression within the OVLT and outside the OVLT extending into the preoptic nuclei, dorsally into the ventral median preoptic nucleus, and rostrally into the diagonal band (data now shown). Although light pulses (5 or $10 \mathrm{~ms}$ pulse, $50 \%$ duty cycle, $30 \mathrm{~min}$ ) produced frequency-dependent increases in water intake (data not shown, $\left.n=8 ; F_{(3,21)}=185.080, p=0.000\right)$, the 30 min cumulative water intake was less in these animals versus those animals with expression restricted to the OVLT and reported in Figure $6: 1 \mathrm{~Hz}(0.8 \pm$ $\left.0.3 \mathrm{vs} 1.8 \pm 0.4 \mathrm{ml} ; t_{(14)}=-1.000, p=0.334\right), 5 \mathrm{~Hz}(4.0 \pm 0.5 \mathrm{vs}$ $\left.8.9 \pm 1.0 \mathrm{ml} ; t_{(14)}=-2.489, p=0.0260\right), 10 \mathrm{~Hz}(6.8 \pm 1.0 \mathrm{vs}$ $\left.15.7 \pm 2.8 \mathrm{ml} ; t_{(14)}=-1.839, p=0.08724\right)$, and $20 \mathrm{~Hz}(9.5 \pm 1.5$ vs $\left.19.3 \pm 2.8 \mathrm{ml} ; t_{(14)}=-3.091, p=0.008\right)$.

Another set of experiments was repeated in this same cohort of animals to determine whether optogenetic stimulation of OVLT neurons produced a salt appetite. OVLT $(n=6)$ and OVLT-x $(n=$ 7) rats were placed on a $\mathrm{NaCl}$-deficient $(0.01 \%)$ diet for $7 \mathrm{~d}$ and given access to water and $0.3 \mathrm{M} \mathrm{NaCl}$ solution. Two OVLT rats were removed from this trial as the head cap was dislodged. Optogenetic stimulation of OVLT increased the ingestion of water but not $0.3 \mathrm{M} \mathrm{NaCl}$ (Fig. 7A). A two-way ANOVA fluid $\times$ time) $_{\text {revealed }}$ a significant effect for fluid $\left(F_{(1,10)}=15.354, p=0.002\right)$, time $\left(F_{(3,30)}=24.085, p=0.000\right)$, and interaction $\left(F_{(3,30)}=11.751\right.$, $p=0.000)$. However, a main effect was significant for water intake $\left(F_{(3,15)}=22.740, p=0.000\right.$ ANOVA) but not $0.3 \mathrm{M} \mathrm{NaCl}$ $\left(F_{(3,15)}=2.461, p=0.102\right.$ ANOVA). Post hoc tests revealed that rats ingested significantly more water than $0.3 \mathrm{M} \mathrm{NaCl}$ at every time point (Fig. 7A). Analysis of urinary volume revealed a significant effect $\left(F_{(3,15)}=4.340, p=0.0217\right.$ ANOVA); however, post hoc comparisons (paired $t$ tests with layered Bonferroni correction) did not reveal a statistical increase in urine volume from baseline values. Figure $7 B$ illustrates cumulative $30 \mathrm{~min}$ water and $0.3 \mathrm{~m} \mathrm{NaCl}$ intake and latency to drink for OVLT and OVLT-x rats. A two-way $\mathrm{ANOVA}_{\text {(fluid, group) }}$ of $30 \mathrm{~min}$ water intakes indicated a significant effect of fluid $\left(F_{(1,11)}=33.147, p=0.000\right)$, group $\left(F_{(1,11)}=14.963, p=0.003\right)$, and interaction $\left(F_{(1,11)}=\right.$ $12.045, p=0.005)$. OVLT rats ingested more water than OVLT-x and ingested more water than $0.3 \mathrm{M} \mathrm{NaCl}$ (Fig. $7 B$ ). In addition, a two-way ANOVA $_{\text {(fluid }} \times$ group) of latency to drink indicated a significant effect of fluid $\left(F_{(1,11)}=35.837, p=0.000\right)$, group $\left(F_{(1,11)}=8.606, p=0.014\right)$, but no interaction $\left(F_{(1,11)}=0.397\right.$, $p=0.543)$. OVLT rats displayed a shorter latency to drink versus OVLT-x rats for the ingestion of water and $0.3 \mathrm{M} \mathrm{NaCl}$ (Fig. 7B). It is noteworthy that no OVLT-x rats drank $0.3 \mathrm{M} \mathrm{NaCl}$.

\section{Optogenetic inhibition of OVLT neurons reduces thirst stimulated by hypernatremia and hypotension}

A final set of experiments was performed to test whether thirst stimulated by hypernatremia or elevated AngII depends on OVLT neurons. Infusion of $2 \mathrm{M} \mathrm{NaCl}$ increased the ingestion of water in rats; however, water intake was significantly lower in rats with the laser continuously ON versus OFF (Fig. 8A, left). A two-way ANOVA $_{(\text {light } \times \text { time) }}$ of water intake indicated a significant effect of

\section{B, $\square$ OVLT and $\square$ OVLT-x}
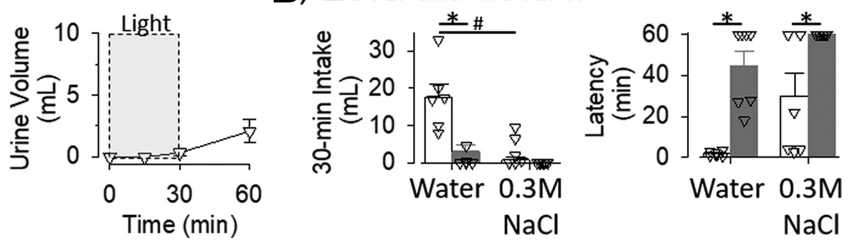

$\mathrm{NaCl}$

$\left.F_{(1,11)}=25.725, p=0.000\right)$, time $\left(F_{(3,33)}=22.681, p=\right.$ $0.000)$, and interaction $\left(F_{(3,33)}=11.691, p=0.000\right)$. These differences were observed despite no difference in urinary volume.

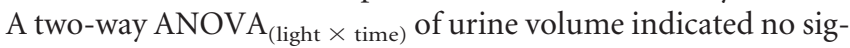
nificant difference between groups $\left(F_{(1,11)}=2.93801, p=0.115\right)$ or interaction $\left(F_{(3,33)}=0.83415, p=0.485\right)$, but there was a significant effect of time $\left(F_{(3,33)}=31.752, p=0.000\right)$. A subsequent comparison between rats infused with $2 \mathrm{M} \mathrm{NaCl}$ with the light OFF versus continuously $\mathrm{ON}$ versus $\mathrm{ON}$ at $20 \mathrm{~Hz}$ revealed rats with the light continuously $\mathrm{ON}$ ingested significantly less water (Fig. $8 A$, right; $F_{(2,15)}=7.645, p=0.005$, ANOVA) and the latency to drink was longer (Fig. $8 A$, right; $\left(F_{(2,15)}=3.850, p=\right.$ 0.045, ANOVA).

Since AngII administered systemically is not a powerful dipsogen due to the parallel increase in blood pressure (Robinson and Evered, 1987; Stocker et al., 2002), rats were given an intravenous injection of the vasodilator diazoxide which produces an AngII-dependent thirst (Evered, 1990; Stocker et al., 2003). The same cohort of animals was used as the hypertonic $\mathrm{NaCl}$ experiments, except 1 rat was excluded due to a dislodged head cap. Injection of diazoxide stimulated the ingestion of water in rats; however, water intake was significantly lower in rats with the laser continuously ON versus OFF (Fig. $8 B$, left). A two-way ANOVA $_{\text {(light } \times \text { time) }}$ of water intake indicated a significant effect of light $\left(F_{(1,10)}=\right.$ $17.8115, p=0.002)$, time $\left(F_{(3,30)}=17.746, p=0.000\right)$, but not interaction $\left(F_{(3,30)}=0.422, p=0.738\right)$. These differences were observed despite no difference in urinary volume. A two-way

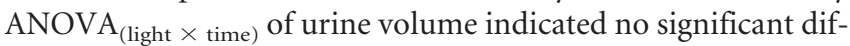
ference between groups $\left(F_{(1,11)}=0.260, p=0.621\right)$ or interaction $\left(F_{(3,30)}=0.992, p=0.385\right)$, but there was a significant effect of time $\left(F_{(3,30)}=10.120, p=0.001\right)$. A subsequent comparison between rats injected with diazoxide and the light OFF versus continuously $\mathrm{ON}$ versus $\mathrm{ON}$ at $20 \mathrm{~Hz}$ revealed that rats with the light continuously ON ingested significantly less water (Fig. $8 B$, right; $F_{(2,14)}=13.274, p=0.001$, ANOVA), but the latency to drink was not statistically longer (Fig. $8 B$, right; $F_{(2,14)}=3.438$, $p=0.061$, ANOVA). Figure $8 C$ illustrates a schematic diagram of OVLT injection sites and a representative example. Again, mCherry expression did not extend dorsally into the median preoptic nucleus, rarely extended rostrally into the diagonal band of Broca, and stopped caudally within $200 \mu \mathrm{m}$ at the start of the third ventricle.

Finally, to test whether optogenetic inhibition of OVLT neurons attenuates thirst to all stimuli, cumulative water intake and latency to drink were recorded in animals made hypovolemic by subcutaneous injection of $20 \%$ PEG. Rats with or without optogenetic inhibition of OVLT neurons significantly increased water intake after PEG treatment (Fig. 9A, left). A twoway ANOVA $_{(\text {light }} \times$ time) of water intake indicated no significant 

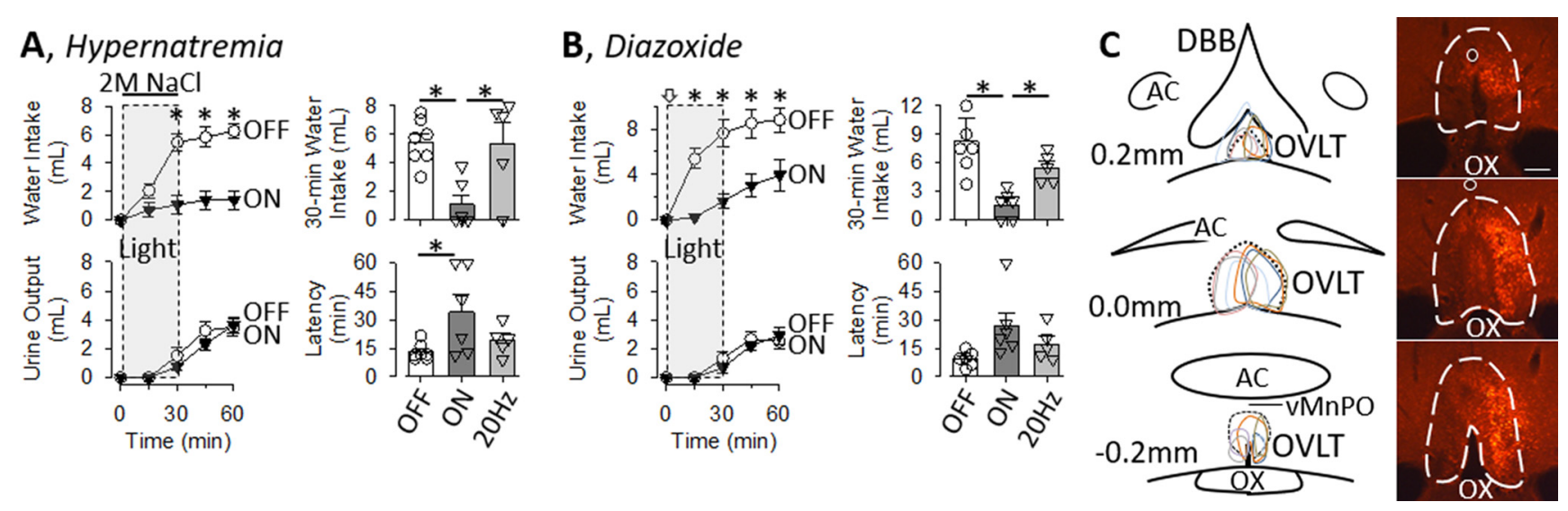

Figure 8. A, Left, Mean \pm SEM of cumulative water intake and urine output of rats infused with $2 \mathrm{M} \mathrm{NaCl}$ and $561 \mathrm{~nm}$ light $0 \mathrm{FF}(n=7)$ or continuously $0 \mathrm{~N}(n=6)$ for 30 min separated by $3 \mathrm{~d}$. ${ }^{*} p<0.05,0 \mathrm{FF}$ versus $\mathrm{ON}$ ( $t$ tests with layered Bonferroni correction; for ANOVA, see text). Right, Mean \pm SEM and data points of 30 min water intake and latency to drink or rats infused with $2 \mathrm{M}$ $\mathrm{NaCl}$ and $571 \mathrm{~nm}$ light $0 \mathrm{FF}$, continuously $\mathrm{ON}$, and $\mathrm{ON}$ at $20 \mathrm{~Hz}$ ( 2 s ON, 2 s $0 \mathrm{FF}, 50 \%$ duty cycle for $30 \mathrm{~min}$ ). ${ }^{*} p<0.05$ versus $0 \mathrm{~N}$ (Fisher's LSD; for ANOVA, see text). $\boldsymbol{B}$, Left, Mean \pm SEM of cumulative water intake and urine output of rats receiving a bolus injection of diazoxide $(25 \mathrm{mg} / \mathrm{kg}$, i.v.) and $571 \mathrm{~nm}$ light $0 \mathrm{FF}(n=6)$ or continuously $0 \mathrm{~N}(n=6)$ for $30 \mathrm{~min}$ separated by $3 \mathrm{~d}$. $p<<0.05,0 \mathrm{FF}$ versus $0 \mathrm{~N}$ ( $t$ tests with layered Bonferroni correction; for ANOVA, see text). Right, Mean \pm SEM and data points of 30 min water intake and latency to drink or rats given diazoxide and $561 \mathrm{~nm}$ light OFF, continuously $\mathrm{ON}$, and $\mathrm{ON}$ at $20 \mathrm{~Hz}$ ( $2 \mathrm{~s} \mathrm{ON}, 2 \mathrm{~s} 0 \mathrm{FF}, 50 \%$ duty cycle for $30 \mathrm{~min}$ ). ${ }^{*} p<0.05$ versus $\mathrm{ON}$ (Fisher's LSD; for ANOVA, see text). C, Schematic illustration of mCherry expression for $70 \mathrm{VLT}$ rats and digital image of representative mCherry expression and tip of optical ferrule (0). Scare bar, $200 \mu \mathrm{m}$.

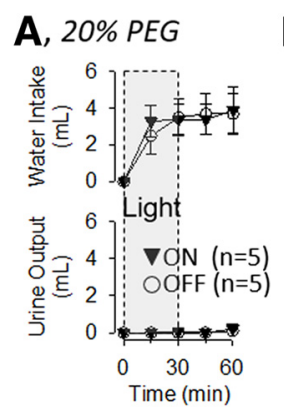

B

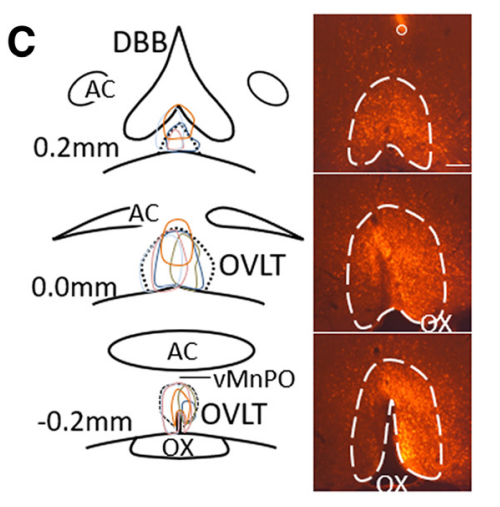

Figure 9. $A$, Mean \pm SEM of cumulative water intake and urine output of rats treated with $20 \%$ PEG $(5 \mathrm{ml}$, s.c.) and $561 \mathrm{~nm}$ light OFF $(n=5)$ or continuously ON $(n=5)$ for $30 \mathrm{~min}$. $B$, Mean \pm SEM and data points of 30 min water intake and latency to drink. There were no significant differences in any variable between rats with the laser $0 \mathrm{~N}$ versus off. C, Schematic illustration of $m$ Cherry expression for 5 OVLT rats and digital image of representative mCherry expression and tip of optical ferrule (0). Scare bar, $200 \mu \mathrm{m}$.

effect of light $\left(F_{(1,8)}=0.0166, p=0.902\right)$ or interaction $\left(F_{(3,24)}=\right.$ $1.164, p=0.343)$ but a significant effect of time $\left(F_{(3,24)}=3.106\right.$, $p=0.04542)$. Rats did not excrete any urine during the $30 \mathrm{~min}$ laser application (Fig. 9A). There were no significant differences in 30 min water intakes (Fig. $9 B ; t_{(4)}=0.000, p=1.000$, paired $t$ test) or latency to drink (Fig. $9 B ; t_{(4)}=-0.149, p=0.889$, paired $t$ test) of rats with or without the laser. Figure $9 C$ illustrates a schematic diagram of OVLT injection sites and a representative example for this cohort. mCherry expression was largely localized to the OVLT with limited expression in the median preoptic nucleus, diagonal band of Broca, or $>200 \mu \mathrm{m}$ caudally of the third ventricle. It is noteworthy that 3 rats were excluded (data not shown) after post hoc analysis of mCherry expression revealed injection sites located outside the OVLT $(n=1$ caudal, $n=1$ rostral) or no expression was observed $(n=1)$.

\section{Discussion}

This study provides the first compelling evidence that an individual OVLT neuron responds to both hypertonic $\mathrm{NaCl}$ and AngII. Foremost, both in vitro whole-cell patch clamp and in vivo singleunit recordings revealed that $52 \%-66 \%$ of OVLT neurons increased discharge rate in response to elevated $\mathrm{NaCl}$ and AngII concentrations. Anatomical mapping of electrophysiological identified cells indicates that NaCl- and AngII-responsive neurons are distributed throughout the OVLT. Moreover, optogenetic interrogations demonstrate OVLT neurons contribute to water intake stimulated by acute hypernatremia and AngII but not mild hypovolemia.

A critical aspect of the in vivo and in vitro electrophysiology experiments is the manner by which neurons were identified as $\mathrm{NaCl}$ - or AngII-responsive. The hypertonic $\mathrm{NaCl}$ stimulus (7.5 $\mathrm{mm}$ in vitro or $50 \mu \mathrm{l}$ of $0.5 \mathrm{M} \mathrm{NaCl}$ in vivo) increases osmolality $5 \%-7 \%$ which mirrors similar changes in plasma osmolality after $48 \mathrm{~h}$ water deprivation (Brooks et al., 2004a,b; Stocker et al., 2005). Local AngII concentrations within the OVLT are unknown, but concentrations used here were chosen from previous studies conducted in vitro or in vivo (Gutman et al., 1988; Anderson et al., 2001; Stocker and Toney, 2005). One caveat is that these experiments do not directly assess how OVLT neurons sense NaCl versus AngII but merely whether an individual neuron responds to these stimuli.

Anatomical mapping of Neurobiotin-filled cells after both in vivo and in vitro electrophysiology experiments indicate OVLT neurons responsive to $\mathrm{NaCl}$ and AngII were diffusely distributed throughout the OVLT. This observation directly conflicts with the anatomical distribution of Fos immunoreactivity of the rat localized to the dorsal cap during acute hypernatremia versus the core after elevated AngII levels as reported previously (Oldfield et al., 1991, 1994; McKinley et al., 1992; Shi et al., 2008) and con- 
firmed here (Fig. 1). How then do we reconcile these conflicting observations? No anatomic differences exist within the OVLT on the basis of neuronal density or cytoarchitecture to explain these divergent response distributions or upon which to distinguish these subregions (Prager-Khoutorsky and Bourque, 2015). Fos is not expressed in all neurons and may not always reflect neuronal discharge (Dragunow and Faull, 1989; Luckman et al., 1994). Thus, one possible explanation is that Fos immunoreactivity does not accurately reflect the entire population of responsive cells. On the other hand, $\mathrm{NaCl}$ and AngII increase Fos immunoreactivity in overlapping neurochemical populations of mouse OVLT neurons expressing the vesicular glutamate transporter-2 or nitric oxide synthase (Zimmerman et al., 2016; Leib et al., 2017; Augustine et al., 2018). This observation has been confirmed in mice using in vivo calcium imaging and photometry (Zimmerman et al., 2016; Leib et al., 2017; Augustine et al., 2018). While there may be species differences between rats versus mice, the anatomical versus neurochemical distribution of $\mathrm{NaCl}$ versus AngIIresponsive cells and approaches used may explain differences in the location of $\mathrm{NaCl}$ versus AngII-responsive neurons.

OVLT neurons play a pivotal role in thirst, the secretion of vasopressin or antidiuretic hormone, and sympathetic nerve activity during hypernatremia (McKinley et al., 2003; Bourque, 2008; Kinsman et al., 2017c). Electrolytic lesion of the OVLT in dogs attenuated thirst stimulated by acute hypernatremia and elevated AngII but not hemorrhage (Thrasher et al., 1982; Thrasher and Keil, 1987). Such studies in rodents are absent as lesions have targeted the anteroventral third ventricular region, which includes OVLT, median preoptic, fibers from SFO, and other preoptic nuclei (Buggy and Johnson, 1977a,b). Recent optogenetic interrogations report that stimulation of OVLT neurons promotes thirst (Zimmerman et al., 2016; Leib et al., 2017; Augustine et al., 2018). The present findings confirm these observations as optogenetic activation of OVLT CaMKII neurons produces a frequency-dependent increase in water intake. It is noteworthy that both the cumulative water intake and latency to drink were not different between 10 and $20 \mathrm{~Hz}$. This is important as in vivo single-unit recordings have never reported discharge frequencies of OVLT neurons $>10 \mathrm{~Hz}$ in response to physiological stimuli, such as $\mathrm{NaCl}$ or AngII (Honda et al., 1990; Kinsman et al., 2017b, c). The rapid and immediate ingestion of water occurred despite no increase in urine volume, suggesting either a delayed gastric emptying or elevated circulating vasopressin levels to promote renal water reabsorption. Despite a profound effect on thirst, a two-bottle test revealed that activation of OVLT neurons using 20 $\mathrm{Hz}$ stimulation did not produce a robust salt appetite as also reported in mice (Leib et al., 2017). Together, these findings indicate that selective activation of OVLT neurons primarily stimulates thirst.

A key novel finding of this study is that OVLT neurons contribute to thirst stimulated by $\mathrm{NaCl}$ or AngII. Optogenetic inhibition of OVLT CaMKII neurons using continuous, but not intermittent, light blunted thirst in response to intravenous infusion of $2 \mathrm{M} \mathrm{NaCl}$ or injection of the vasodilator diazoxide. Hypotension-induced thirst is mediated by the release of renin and production of AngII (Evered, 1990). These findings support cellular data regarding the presence of $\mathrm{NaCl}$ - and AngII-responsive neurons in the OVLT (Oldfield et al., 1991, 1994; McKinley et al., 1992; Shi et al., 2008; Zimmerman et al., 2016; Leib et al., 2017; Augustine et al., 2018) and electrophysiological data presented here. In addition, these findings also confirm the original observations that electrolytic lesion of the OVLT in dogs attenuated thirst stimulated by acute hypernatremia and elevated AngII
(Thrasher et al., 1982; Thrasher and Keil, 1987). Optogenetic inhibition of OVLT neurons did not generally disrupt drinking behavior as cumulative water intake and latency to drink in response to mild hypovolemia were unaffected. These findings corroborate original observations in dogs that electrolytic lesion of OVLT did not attenuate water intake or vasopressin secretion during hemorrhage (Thrasher and Keil, 1987) as well as normal thirst responses to PEG in AV3V-lesioned rats (Buggy and Johnson, 1977b). Together, these observations suggest OVLT neurons play a pivotal role in homeostatic responses to elevation in $\mathrm{NaCl}$ concentrations or plasma AngII levels.

The putative signaling mechanisms by which $\mathrm{NaCl}$ and AngII regulate the activity of OVLT neurons remain uncertain. Evidence from radioligand binding studies and transgenic reporter mice suggest that OVLT neurons express an abundance of AngII type 1 receptors (Allen et al., 1988; Song et al., 1992; Leib et al., 2017). OVLT neurons can detect changes in extracellular $\mathrm{NaCl}$ and osmolality, but the mechanisms for each may differ. For instance, hypertonic $\mathrm{NaCl}$ evokes a significantly greater increase in OVLT neuronal discharge than equiosmotic mannitol (Kinsman et al., 2017b). Moreover, hypertonic $\mathrm{NaCl}$ and equiosmotic mannitol both stimulate thirst (Bourque, 2008; Kinsman et al., 2014), but only $\mathrm{NaCl}$ raises sympathetic nerve activity (Kinsman et al., 2017b). Although an N-terminal variant of the transient receptor vanilloid type 1 channel mediates the intrinsic osmosensitivity of OVLT neurons in vitro (Ciura and Bourque, 2006; Ciura et al., 2011), the cellular mechanisms involved in $\mathrm{NaCl}-$ sensing remain elusive. Nomura et al. (2019) recently reported that $\mathrm{NaCl}$ is sensed by glial $\mathrm{NaX}$ channels to stimulate local $\mathrm{H}^{+}$ release to depolarize OVLT neurons. Oddly, none of the $\mathrm{NaCl}-$ sensitive OVLT neurons were excited by mannitol, the magnitude of the $\mathrm{NaCl}$ stimulus exceeds any physiological range, and the injection volumes into OVLT (or SFO) of the mouse were far greater (5- to 10-fold) (Matsuda et al., 2017; Nomura et al., 2019) than ones used here in rats. Whether $\mathrm{NaCl}$ and AngII converge onto OVLT neurons to synergistically regulate neuronal activity is not known.

The current findings provide the first electrophysiological evidence that individual OVLT neurons respond to $\mathrm{NaCl}$ and $\mathrm{An}$ gII. Such neurons were widely distributed throughout the OVLT, including the core and dorsal cap. Functionally, OVLT neurons play a pivotal role in body fluid homeostasis by driving thirst and promoting renal water conservation. Selective inhibition of OVLT neurons attenuated thirst stimulated by acute hypernatremia and elevated AngII. Collectively, these studies illustrate that OVLT neurons play a pivotal role to respond to neurohumoral factors that impact body fluid homeostasis.

\section{References}

Allen AM, McKinley MJ, Mendelsohn FA (1988) Comparative neuroanatomy of angiotensin II receptor localization in the mammalian hypothalamus. Clin Exp Pharmacol Physiol 15:137-145.

Anderson JW, Smith PM, Ferguson AV (2001) Subfornical organ neurons projecting to paraventricular nucleus: whole-cell properties. Brain Res 921:78-85.

Augustine V, Gokce SK, Lee S, Wang B, Davidson TJ, Reimann F, Gribble F, Deisseroth K, Lois C, Oka Y (2018) Hierarchical neural architecture underlying thirst regulation. Nature 555:204-209.

Betley JN, Xu S, Cao ZF, Gong R, Magnus CJ, Yu Y, Sternson SM (2015) Neurons for hunger and thirst transmit a negative-valence teaching signal. Nature 521:180-185.

Bourque CW (2008) Central mechanisms of osmosensation and systemic osmoregulation. Nat Rev Neurosci 9:519-531.

Brooks VL, Freeman KL, O’Donaughy TL (2004a) Acute and chronic increases in osmolality increase excitatory amino acid drive of the rostral 
ventrolateral medulla in rats. Am J Physiol Regul Integr Comp Physiol 287:R1359-R1368.

Brooks VL, Freeman KL, Clow KA (2004b) Excitatory amino acids in rostral ventrolateral medulla support blood pressure during water deprivation in rats. Am J Physiol Heart Circ Physiol 286:H1642-H1648.

Buggy J, Johnson AK (1977a) Anteroventral third ventricle periventricular ablation: temporary adipsia and persisting thirst deficits. Neurosci Lett 5:177-182.

Buggy J, Johnson AK (1977b) Preoptic-hypothalamic periventricular lesions: thirst deficits and hypernatremia. Am J Physiol 233:R44-R52.

Ciura S, Bourque CW (2006) Transient receptor potential vanilloid 1 is required for intrinsic osmoreception in organum vasculosum lamina terminalis neurons and for normal thirst responses to systemic hyperosmolality. J Neurosci 26:9069-9075.

Ciura S, Liedtke W, Bourque CW (2011) Hypertonicity sensing in organum vasculosum lamina terminalis neurons: a mechanical process involving TRPV1 but not TRPV4. J Neurosci 31:14669-14676.

Dragunow M, Faull R (1989) The use of c-fos as a metabolic marker in neuronal pathway tracing. J Neurosci Methods 29:261-265.

Evered MD (1990) Relationship between thirst and diazoxide-induced hypotension in rats. Am J Physiol 259:R362-R370.

Gutman MB, Ciriello J, Mogenson GJ (1988) Effects of plasma angiotensin II and hypernatremia on subfornical organ neurons. Am J Physiol Regul Integr Comp Physiol 254:R746-R754.

Honda K, Negoro H, Dyball RE, Higuchi T, Takano S (1990) The osmoreceptor complex in the rat: evidence for interactions between the supraoptic and other diencephalic nuclei. J Physiol 431:225-241.

Kinsman BJ, Cowles J, Lay J, Simmonds SS, Browning KN, Stocker SD (2014) Osmoregulatory thirst in mice lacking the transient receptor potential vanilloid type 1 (TRPV1) and/or type 4 (TRPV4) receptor. Am J Physiol Regul Integr Comp Physiol 307:R1092-R1100.

Kinsman BJ, Nation HN, Stocker SD (2017a) Hypothalamic signaling in body fluid homeostasis and hypertension. Curr Hypertens Rep 19:50.

Kinsman BJ, Browning KN, Stocker SD (2017b) NaCl and osmolarity produce different responses in organum vasculosum of the lamina terminalis neurons, sympathetic nerve activity and blood pressure. J Physiol 595: 6187-6201.

Kinsman BJ, Simmonds SS, Browning KN, Stocker SD (2017c) Organum vasculosum of the lamina terminalis detects $\mathrm{NaCl}$ to elevate sympathetic nerve activity and blood pressure. Hypertension 69:163-170.

Leib DE, Zimmerman CA, Poormoghaddam A, Huey EL, Ahn JS, Lin YC, Tan CL, Chen Y, Knight ZA (2017) The forebrain thirst circuit drives drinking through negative reinforcement. Neuron 96:1272-1281.e4.

Leng G, Way S, Dyball RE (1991) Identification of oxytoxin cells in the rat supraoptic nucleus by their response to cholecystokinin injection. Neurosci Lett 122:159-162.

Luckman SM, Dyball RE, Leng G (1994) Induction of c-fos expression in hypothalamic magnocellular neurons requires synaptic activation and not simply increased spike activity. J Neurosci 14:4825-4830.

Matsuda T, Hiyama TY, Niimura F, Matsusaka T, Fukamizu A, Kobayashi K, Kobayashi K, Noda M (2017) Distinct neural mechanisms for the control of thirst and salt appetite in the subfornical organ. Nat Neurosci 20:230-241.

McKinley MJ, Badoer E, Oldfield BJ (1992) Intravenous angiotensin II induces fos-immunoreactivity in circumventricular organs of the lamina terminalis. Brain Res 594:295-300.

McKinley MJ, McAllen RM, Davern P, Giles ME, Penschow J, Sunn N, Uschakov A, Oldfield BJ (2003) The sensory circumventricular organs of the mammalian brain. Adv Anat Embryol Cell Biol 172:III-XII, 1-122, back cover.

Nation HL, Nicoleau M, Kinsman BJ, Browning KN, Stocker SD (2016)
DREADD-induced activation of subfornical organ neurons stimulates thirst and salt appetite. J Neurophysiol 115:3123-3129.

Nomura K, Hiyama TY, Sakuta H, Matsuda T, Lin CH, Kobayashi K, Kobayashi K, Kuwaki T, Takahashi K, Matsui S, Noda M (2019) [ $\mathrm{Na}(+)]$ increases in body fluids sensed by central Nax induce sympathetically mediated blood pressure elevations via $\mathrm{H}(+)$-dependent activation of ASIC1a. Neuron 101:60-75.e6.

Oka Y, Ye M, Zuker CS (2015) Thirst driving and suppressing signals encoded by distinct neural populations in the brain. Nature 520:349-352.

Oldfield BJ, Bicknell RJ, McAllen RM, Weisinger RS, McKinley MJ (1991) Intravenous hypertonic saline induces fos immunoreactivity in neurons throughout the lamina terminalis. Brain Res 561:151-156.

Oldfield BJ, Badoer E, Hards DK, McKinley MJ (1994) Fos production in retrogradely labelled neurons of the lamina terminalis following intravenous infusion of either hypertonic saline or angiotensin II. Neuroscience 60:255-262.

Pinault D (1996) A novel single-cell staining procedure performed in vivo under electrophysiological control: morpho-functional features of juxtacellularly labeled thalamic cells and other central neurons with biocytin or neurobiotin. J Neurosci Methods 65:113-136.

Prager-Khoutorsky M, Bourque CW (2015) Anatomical organization of the rat organum vasculosum laminae terminalis. Am J Physiol Regul Integr Comp Physiol 309:R324-R337.

Robinson MM, Evered MD (1987) Pressor action of intravenous angiotensin II reduces drinking response in rats. Am J Physiol 252:R754-R759.

Shi P, Martinez MA, Calderon AS, Chen Q, Cunningham JT, Toney GM (2008) Intra-carotid hyperosmotic stimulation increases fos staining in forebrain organum vasculosum laminae terminalis neurones that project to the hypothalamic paraventricular nucleus. J Physiol 586:5231-5245.

Song K, Allen AM, Paxinos G, Mendelsohn FA (1992) Mapping of angiotensin II receptor subtype heterogeneity in rat brain. J Comp Neurol 316:467-484.

Stocker SD, Toney GM (2005) Median preoptic neurones projecting to the hypothalamic paraventricular nucleus respond to osmotic, circulating ang II and baroreceptor input in the rat. J Physiol 568:599-615.

Stocker SD, Stricker EM, Sved AF (2002) Arterial baroreceptors mediate the inhibitory effect of acute increases in arterial blood pressure on thirst. Am J Physiol Regul Integr Comp Physiol 282:R1718-R1729.

Stocker SD, Smith CA, Kimbrough CM, Stricker EM, Sved AF (2003) Elevated dietary salt suppresses renin secretion but not thirst evoked by arterial hypotension in rats. Am J Physiol Regul Integr Comp Physiol 284:R1521-R1528.

Stocker SD, Hunwick KJ, Toney GM (2005) Hypothalamic paraventricular nucleus differentially supports lumbar and renal sympathetic outflow in water-deprived rats. J Physiol 563:249-263.

Thrasher TN, Keil LC (1987) Regulation of drinking and vasopressin secretion: role of organum vasculosum laminae terminalis. Am J Physiol 253:R108-R120.

Thrasher TN, Keil LC, Ramsay DJ (1982) Lesions of the organum vasculosum of the lamina terminalis (OVLT) attenuate osmotically-induced drinking and vasopressin secretion in the dog. Endocrinology 110:1837-1839.

Toney GM, Stocker SD (2010) Hyperosmotic activation of CNS sympathetic drive: implications for cardiovascular disease. J Physiol 588:3375-3384.

Tucker AB, Stocker SD (2016) Hypernatremia-induced vasopressin secretion is not altered in TRPV1 ${ }^{-i-}$ rats. Am J Physiol Regul Integr Comp Physiol 311:R451-R456.

Zimmerman CA, Lin YC, Leib DE, Guo L, Huey EL, Daly GE, Chen Y, Knight ZA (2016) Thirst neurons anticipate the homeostatic consequences of eating and drinking. Nature 537:680-684.

Zimmerman CA, Leib DE, Knight ZA (2017) Neural circuits underlying thirst and fluid homeostasis. Nat Rev Neurosci 18:459-469. 